To appear in D. Carlston, K. Johnson, \& K. Hugenberg (Eds.), The Oxford Handbook of Social Cognition, $2^{\text {nd }}$ ed. (forthcoming)

Gender as Embedded Social Cognition

Amanda B. Diekman

Indiana University

Toni Schmader

University of British Columbia

Submitted version of December 14, 2020

Corresponding author: Amanda Diekman, Department of Psychological and Brain Sciences, Indiana University; abdiekma@iu.edu 


\begin{abstract}
We examine gender as a cultural construct enacted through social cognitive processes that are embedded within the self, social interactions, and societal institutions. The embeddedness perspective elaborates how the binary gender categorization can create quite real gendered outcomes and experiences even if gender differences are not biologically essential. These categories take on a reality outside of the mind of perceivers because the meanings attached to gender categories are shared by others in the culture, enacted in social interactions, internalized into self-views, and maintained by social systems. Societal institutions explicitly and implicitly organize around gender, producing gendered norms, roles, and expectations. These norms, roles, and expectations shape the nature of interpersonal interactions both within and across gender lines and an individual's self-selected experiences. Critically, these social interactions and personal choices in turn create behavioral and cognitive confirmation of the gendered expectations of others. Gendered expectations and experiences become internalized into the self, including one's own self-concept and gender identity. We close by examining implications of this perspective for gender differences and similarities in social cognition, as well as malleability and stability in gender cognitions and outcomes.
\end{abstract}




\section{Gender as Embedded Social Cognition}

Gender is one of the earliest and easiest ways we categorize others and ourselves. And yet, increasingly, what exactly gender is and how it shapes perception and identity are under debate. In this context, considering gender from a social cognitive standpoint is timely both practically and theoretically. We examine gender as a cultural construct enacted through social cognitive processes that are embedded within the self, social interactions, and societal institutions. From this standpoint, gendered cognitions are produced and maintained in a broader system where culture and selves mutually constitute one another (Markus \& Kitayama, 2010). Social cognition is not social only because it focuses on social information; it is social in the reasons for engaging in those processes, in the contexts that such processes occur, and in the broader sociocultural structure that shapes both the content and the process of cognition. In this chapter, we synthesize evidence for this view of gender as embedded within culture. In doing so, we provide clearer definitions of gendered cognitions as aspects of identity and self-expression, stereotypes and attitudes about others, and reinforced in roles and social norms. We will explore how gender is mutually constituted between individual, interpersonal, and institutional levels of analysis. Finally, we will consider the implications of this framework for considering gender differences in how we perceive others and the malleability of gender roles.

\section{The Gender Embeddedness Framework}

This chapter delineates the ways in which cognitive processes are essential to the creation and perpetuation of gender: In short, gender-related cognitions are the fuel that allow the multiple levels of culture to exert influence. We acknowledge that this treatment, given our focus on social cognition, largely does not speak to how biological factors intersect with these processes (Eagly \& Wood, 2013). Here, we review cognitions that both emanate from and contribute to gendered observations and experiences within the self, social interaction, and societal systems (see Figure 1). At each of these levels, gender can be an organizing feature in which the wide range of human behavior and psychology is simplistically grouped into two categories; this dichotomous categorization is referred to as the gender/sex binary (Morgenroth \& Ryan, 2020). The embeddedness perspective elaborates how this binary categorization can create quite real gendered outcomes and experiences even if gender differences are not themselves biologically essential. Gendered categories do not exist only in the mind of the perceiver; these categories take on a reality outside of an individual perceiver because the meanings attached to gender categories are shared by others, internalized into self-views, and maintained by social systems. Contextual cues make gender-related cognitions more or less relevant in different situations. However, because those cues are often maintained and stabilized by shared beliefs and institutional structures, the experiences of people categorized as men or women can differ markedly, even if they appear to be in the same social setting or interaction. Gender thus differentiates experiences in families, jobs, interactions, and societal institutions.

A key point of this embeddedness perspective is that gender cognition is reinforced across different levels: Even if individual-level cognition is less traditionally gendered (i.e., an individual does not attach traditional meaning or value to gender categories), individuals can interact with others and engage with societal institutions that might make gendered cognition relevant. Conversely, institutions that set out to de-emphasize gender or challenge gender disparities must contend with individuals or scripted interactions that can be highly gendered. Further, challenging the gender binary can set into 
motion motivational and cognitive processes that reinforce the binary itself (Morgenroth \& Ryan, 2020). Put simply, to de-emphasize gender, not only individuals but interpersonal interactions and institutions would need to change.

Figure 1 Gender embedded in societal institutions, interactions, and individuals

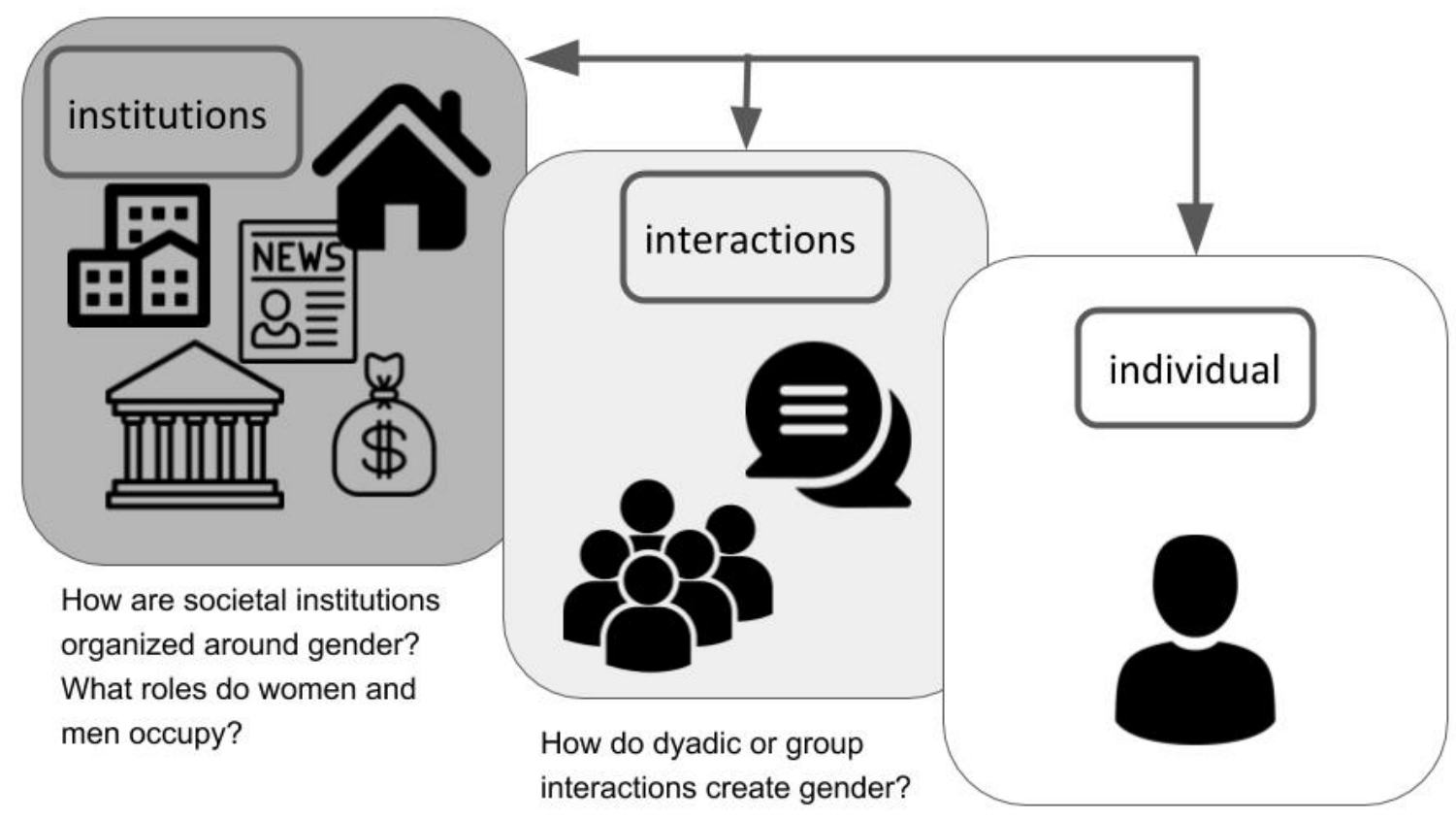

How is gender encoded in the self?

\section{Defining Gendered Cognitions}

We start by considering the specific gendered cognitions that have been documented at the level of the individual, interpersonal interactions, and societal institutions and structures. Figure 2 provides an overview of the key gender cognitions reviewed here. What does it mean for cognition to be embedded at these different levels? First, cognitions are about targets at each level - we review genderrelated cognitions about the self, about groups, and about roles. Second, these gendered cognitions are formed through input from each level - that is, we form beliefs and attitudes through experiences within and observations of societal institutions, during interpersonal interactions, and from individual events. Third, gendered cognitions have impact at each level. Beliefs and attitudes related to gender influence how individuals interact with others and constitute societal institutions. Gendered cognitions thus can exist in the mind of the perceiver, but they are embedded across levels of individual, social, and societal experience. 


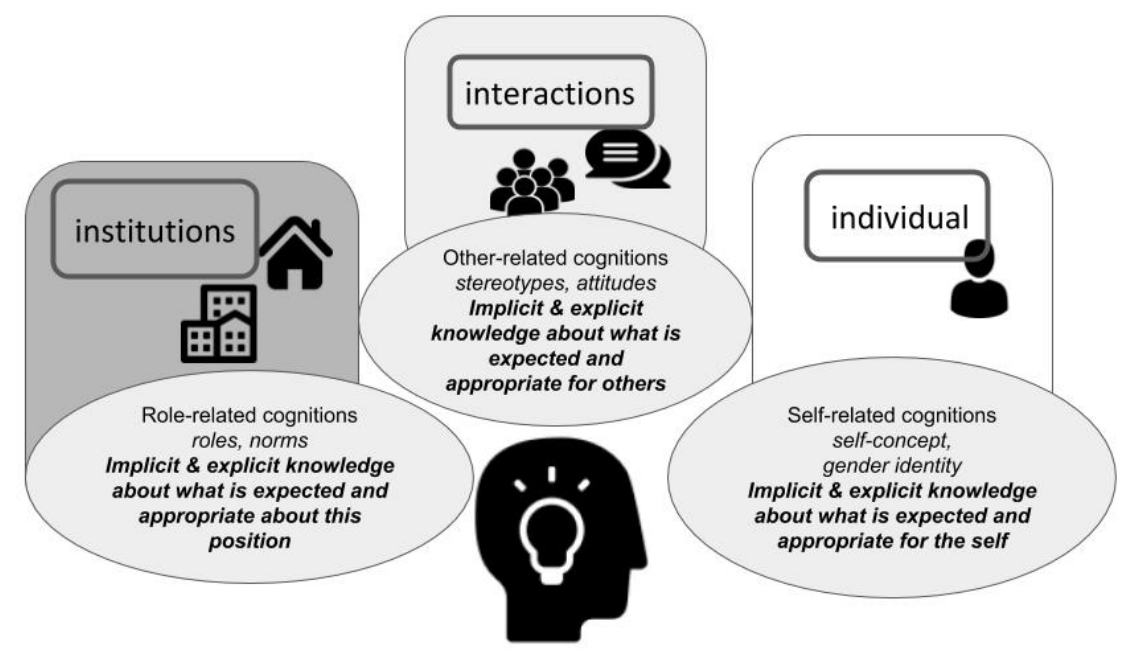

\section{Cognitions about the self: Gender identity and gender expression in the self-concept}

People are born with biological characteristics that identify their assigned sex as female or male (except in rare cases of people who are intersex and have a combination of female and male anatomical and/or chromosomal characteristics). But whereas assigned sex is typically considered a biological construct, gender at the individual level is a social construct that includes components of gender identity and gender expression, two aspects of the gendered self (Schmader \& Block, 2015; Wood \& Eagly, 2015). Sexual orientation, which includes sexual attraction to individuals of a certain sex, is yet another distinct personal attribute related to both culture and biology (van Anders, 2015) that has both prescribed forms of socialized expression (Herek, 1986) and roots in biological mechanisms (Bailey et al., 2016). Because our focus here is on gendered cognitions, rather than sexual attraction, a review of the literature on sexual orientation falls outside of the scope of this chapter.

One's gender identity refers to the way in which one categorizes oneself within a particular gendered social group. Although most individuals identify within the traditional gender categories of boy/girl or man/woman, some individuals instead describe their gender identity as nonbinary or gender fluid, and nonbinary groupings are more present and visible in some cultures (e.g., Herdt, 1993; Independent Lens, 2015). Once an individual has categorized themselves within a gender group, their self-concept is then shaped by this social identity, consistent with social identity theory (Tajfel, 1981). The degree to which this occurs might depend, however, upon the strength of association or centrality of gender to one's sense of self (Crane \& Markus, 1982; Nosek et al., 2002).

Conceptually distinct from one's gender identity is an individual's gender expression, or the degree to which they exhibit traits, preferences, and behaviors typically associated more with men and/or with women. Gender can thus be performed for both the self and others through actions associated with the gender/sex binary (Morgenroth \& Ryan, 2020). At a social cognitive level, this expression of gender has implications for an individual's self-concept, and in particular the genderassociated traits one uses to describe the self. Initially, masculinity-femininity was characterized as a unidimensional construct that was tautologically defined as any characteristics that differentiated males 
and females (see Wood \& Eagly, 2015 for a review). Pioneering work by Bem (1974) and Spence and Helmreich (1978) validated self-report measures that captured two distinct dimensions of gender expression (e.g., instrumentality and expressiveness) that could be distinguished from gender identity. This early work provided theoretical advances in the social cognition of gender in two ways. First, these frameworks clarified that individuals' gender identity (e.g., as male or female) might differ from their gender expression in terms of self-concept. (e.g., instrumentality or expressiveness; Markus et al., 1982). Further, these frameworks documented that the gendered self-concept was not categorical or oppositional; rather than simply demarcating individuals as male or female, these measures of gender expression allowed individuals to express high levels of either, both, or neither trait dimension (e.g., high levels of both masculinity and femininity; Bem, 1974).

The acknowledgement that individuals express their gender in a range of ways presaged the modern expansion of these frameworks through greater awareness and inclusion of nonbinary identities (Hyde et al., 2019). In modern social psychological research, the variability in gender expression in the self-concept is often captured with measures of communion and agency (rather than femininity/masculinity or instrumentality/expressiveness). Communion refers to an orientation toward helping, caring for, and connecting with others, whereas agency refers to an orientation toward promoting, protecting, and advancing one's goals. Although these two factors are often identified as the core dimensions on which all human behavior varies (Abele \& Wojciszke, 2007; Bakan, 1966; Fiske et al., 2007; Judd et al., 2005), the fact that they are often confounded with gender has made them gendered constructs (Martin \& Slepian, 2020; Sczesny et al., 2019). Notably, the extent to which agency and communion reflect gender stereotypes also differs by other intersections, including race and class: What is generally considered the "female stereotype" aligns more with beliefs about White than Black women (e.g., Landrine, 1985).

In closing this section, we note that accumulating evidence provides multiple challenges to the binary categorization of the self as male or female. Cisgender individuals are individuals whose assigned sex aligns with their identified and expressed gender later in life; the bulk of psychological research focuses on cisgender experience. Transgender individuals are those whose identified or expressed gender differs from their assigned sex. Emerging research shows that cisgender and transgender children show similarity in their gender identity and gender constancy (Gülgöz et al., 2019). To date, scientific research including nonbinary individuals is in its infancy; this dearth itself demonstrates how thoroughly the binary category of gender is embedded in cultural practices despite estimates that approximately 1 in every 250 adults in America is transgender (Meerwik \& Sevelius, 2017). Scientists as well as individuals are beginning to challenge this binary categorization, and where possible, we will draw attention to ways that future research could expand the understanding of the how the embeddedness of gender affects those who identify as transgender or nonbinary.

\section{Cognitions about others: Stereotypes and attitudes}

Gender is not only a cognition used to describe the self; it also forms a basis for how we perceive others. When someone's gender influences our expectations about them, it does so through the activation and application of gender stereotypes (Ellemers, 2018). A stereotype is defined as "a set of beliefs about a group of people" (Ashmore \& Del Boca, 1981). Stereotypes can thus include information that is positive or negative, or accurate or inaccurate when comparing group averages. 
Gender stereotypes primarily focus on the traits that are differentially ascribed to women and men, but can also include beliefs about typical behaviors, physical attributes, or activities (Deaux \& Lewis, 1984).

Importantly, stereotypes about groups are summary cognitions that can be both descriptive and prescriptive. Descriptive stereotypes provide information about the typical characteristics of group members, whereas prescriptive stereotypes provide information about the ideal or desired characteristics of group members (Fiske \& Stevens, 1993). Prescriptive beliefs about men include traits aligned with agency or competence, whereas prescriptive beliefs about women include traits aligned with communality or warmth (Eagly et al., 2019; Fiske et al., 2002).

Proscriptive beliefs delineate the behaviors or traits that are prohibited for each gender group namely, indicators of weakness for men and indicators of dominance for women. In samples of US college students (Prentice \& Carranza, 2002), intensified prescriptions for women in US society include the attributes "warm and kind" and "interested in children," whereas intensified prescriptions for men in US society include attributes such as "business sense," "athletic," and "leadership ability." Conversely, intensified proscriptions for women in US society include "rebellious," "stubborn," and "controlling." Intensified proscriptions for men in US society include "emotional," "approval seeking," and "impressionable."

Distinct from stereotypes are the attitudes people hold about the gender groups. Because of dominant stereotypes of women as more communal than men and men as more aggressive than women, people tend to hold more favorable attitudes toward women than men (Rudman et al., 2001; Rudman \& Goodwin, 2004). However, people readily subdivide large social categories into subgroups, and binary gender stereotypes can contain a multitude of subtypes (e.g., Six \& Eckes, 1991). As a result, people often simultaneously hold both positive and negative attitudes toward different subgroups of women (Fiske et al., 2002). For example, people can feel both hostile toward feminists who are seen as pushing too aggressively for gender equality while also idolizing women in traditional roles for having a moral purity (Glick \& Fiske, 2001).

It is important to note that stereotypic beliefs and attitudes about women and men can exist in both explicit and implicit forms. Explicit stereotypes and attitudes are beliefs that are known to individuals and can be stated verbally as propositional statements (Gawronski \& Bodenhausen, 2006). Implicit stereotypes and attitudes reflect learned cognitive associations between attributes and a gender group. Implicit and explicit cognitions need not be correlated with one another (Nosek, 2007). Implicit associations often reflect a history of learned associations that can be automatically activated by exemplars, contexts, or category labels and reflected in everyday language (DeFranza et al., 2020). In contrast, explicit stereotypes and attitudes are more easily shaped by or reflect one's deliberately expressed beliefs and values.

\section{Cognitions related to social structure: Roles, status, and norms}

At the broader institutional or societal level, gendered cognitions include expectations and attitudes about appropriate and valued roles and norms. At this level, the gender hierarchical structure of society, the distribution of social roles, and cultural norms are key cognitions that create and perpetuate gender.

All societies contain some degree of social hierarchy (Sidanius \& Pratto, 1999). In the vast majority, men - by virtue of having control over the economic means of production - are viewed as 
having greater status (Alesina et al., 2013). Once this perception of status is in place, any behaviors or traits associated with the higher status group are then also seen as having greater value and importance (Berger et al., 1985; Ridgeway, 1992; Schmader et al., 2001). For example, when the proportion of women in an occupation increases by 10 percentage points, there is an 8-11\% decrease in wages (Harris, 2019). Longitudinal analyses using census data from 1950 through 2000 find that wages fall after women enter occupations (consistent with a devaluation explanation) rather than women selecting into lowerwage occupations (Levanon et al., 2009). Such findings point to the way in which cognitions that connect men to power and status have ramifications in the social structure.

Social groups both spontaneously create hierarchical structures and distinct normative roles for individuals to perform within that hierarchy (Henrich \& Boyd, 2008). This often, if not always, includes a gendered division of labor that creates strong norms about the roles that men and women should and do occupy. Most societies divide at least some labor along gender lines, although the particular tasks may vary across time and place (Wood \& Eagly, 2002). Women traditionally hold primary responsibility for caregiving and men hold primary responsibility for economic provision and decision making. This division of labor is elaborated culturally through gender roles, a set of expected activities or functions for each gender. The gendered division of labor leads to expectations about the traits and behaviors that make women and men uniquely suited for the roles they have traditionally occupied. In particular, public-sphere and leadership roles (traditionally held by men) are associated with agency, or the ability for the self to act on the world. Private-sphere and caregiving roles (traditionally held by women) are associated with communality, or connection to and care for others. The positioning of gender groups into social roles is also patterned by race, which gives rise to different expectations and penalties for White, Black, or Asian women among US participants (Rosette et al., 2016): Black women are more frequently described as dominant or strong, Asian women as competent and passive, and White women are most likely to be described in terms consistent with traits linked to the general stereotype of women (see also Landrine, 1985).

\section{Is Gender Unique?}

A question that arises is whether the social cognitive constructs and processes involved in gender are fundamentally similar to or different from any other cognitive constructs or processes. On the one hand, the argument for similarity is clear: The specific processes of categorization, encoding, recall, and so on are the same whether we are grouping objects into tables vs. chairs or the binary classification of women vs. men. This is the elegance of understanding cognition as a foundational framework. And yet, we state the obvious by noting there are critical differences between categorizing furniture and categorizing people. Further, there are differences between categorizing by gender and categorizing by other social groupings.

First, gender is ubiquitous in social perception. Of all the ways in which we can perceive people, gender is one of the few that is believed to be universally and immediately encoded when individuals encounter each other (Stangor et al., 1992; Taylor et al., 1978). Even inanimate objects are seen in gendered ways, such as numbers (Wilkie \& Bodenhausen, 2012) or robots and shapes (Stroessner et al., 2020).

Second, because gender is linked to (even if it is not synonymous with) known genetic and physical variation between males and females, there is an especially strong tendency to essentialize 
gender differences as biologically determined and unchangeable (Dar-Nimrod \& Heine, 2006; Meyer \& Gelman, 2016). In novel groups, trait stereotypes linked to group roles are particularly strong when the groups varied in physical features (Hoffman \& Hurst, 1990). We also note that in the case of gender groups, biological features related to reproduction and lactation can contribute to the gendered division of labor (Wood \& Eagly, 2002), which produces gender stereotypes as described earlier. Beliefs about mothers are particularly essentialized, relative to beliefs about fathers (Park \& Banchefsky, 2019). Because biological features differentiate the gender groups, stereotypes about gender groups are more easily formed and internalized, and perhaps harder to change.

Third, the interdependent relationships between men and women lead to complexities in the cognitions for gender that are distinct from those seen for other majority/minority groups. For example, the negotiated yet unequal gender roles and the warmth-based communal stereotypes mean that women as a group are valued in some ways yet stigmatized in others. As we elaborate below, the alliance of women and men in close heterosexual relationships can lead to women's endorsement of stereotypes that rationalize and perpetuate inequality (Rudman \& Glick, 2008).

Finally, although psychological gender is best described as a multidimensional and continuous construct (Carothers \& Reis, 2013), categorization processes dichotomize and simplify this complexity into binary groupings. As a result, even those who do not categorize themselves within the gender binary are still subject to the dominant binary classification by others and embedded in society as a whole. The core thesis of this chapter is that gendered cognitions do not exist isolated from other processes; gender is fundamentally embedded throughout multiple levels of human psychology and social structure, and these levels interact with each other. For example, the presence of gendered categorization in societal institutions sets the stage for contextual effects where gender is more easily made salient in interpersonal interactions, and these interactions shape how people perceive each other and themselves. Conversely, an individual's tendency to perceive interactions and societal institutions through a lens of gender sets in motion confirmatory processes that elicit that very reality.

One feature of the persistent emphasis on binary gender categories is that information that does not fit into this binary can be disregarded, deemphasized, or explained away. Given that scientific research uses the groupings of sex/gender, it plays a role in reifying gender categories and deemphasizing intersectionality (Else-Quest \& Hyde, 2016). In terms of scientific theory and empirical evidence about gender, a consequence is that when gender is the focus, knowledge or theory that considers multiple identities or specific intersections of social categories can fall to the wayside. Research focusing on gender frequently omits other aspects of identity and social group membership, such as race, ethnicity, or social class. Growing knowledge and theory around intersectionality clarifies the need to question assumptions of dominant groupings and consider multiple identities (Cho et al., 2013; Cole, 2009; Crenshaw, 1990). The literature reviewed in this chapter thus reflects the embeddedness of binary gender cognitions; science itself is a societal institution that exemplifies the processes of simplification and amplification that we elaborate here.

\section{How Gender is Embedded in Culture}

Gendered cognitions are embedded at the level of the individual, interpersonal interactions, and social institutions. Gender is an identity and a form of self-expression at the individual level that is perceived, evaluated, and stereotyped by others; and reinforced by societal roles or norms within a 
status hierarchy. We now move on to examining the ways in which gendered conditions both reflect and create experiences at each level. Cognitive processes are not inert; they create new realities. In the case of gender, they create quite distinct realities for those who identify as a man or woman.

Throughout, the three levels are intertwined. Societal institutions explicitly and implicitly organize around gender, producing gendered norms, expectations, and experiences. These norms, expectations, and experiences shape the nature of interpersonal interactions both within and across gender lines. Critically, these social interactions in turn create behavioral and cognitive confirmation of the gendered expectations of others. Gendered expectations and experiences become internalized into the self, including one's own self-concept and gender identity. Thus, whereas we introduced the ideas of various gendered cognitions starting at the individual level, because social forces play a role in defining and constraining one's own gender, here we will begin at the broader institutional level.

\section{Societal Institutions}

Generally speaking, gendered cognitions derive from the position and power of women and men in the larger social structure, and these beliefs contribute to creating and maintaining gender disparities in that context (see Figure 3). The binary gender categories become especially impactful in interactions and in individual psychology because the social order is organized around men and women occupying different social roles both in personal and professional spheres. The meaning of the category is amplified in everyday contexts (e.g., social interactions, social scripts) and in institutional policies and practices (e.g., parental leave, pay disparities). We first examine how gender-differentiated social structure fosters gendered cognition (top arrow in Figure 3 ). We then examine how these cognitions in turn support gendered societal institutions (bottom arrow in Figure 3).

Figure 3 Societal Institutions and Gendered Cognition: Reciprocal Pathways
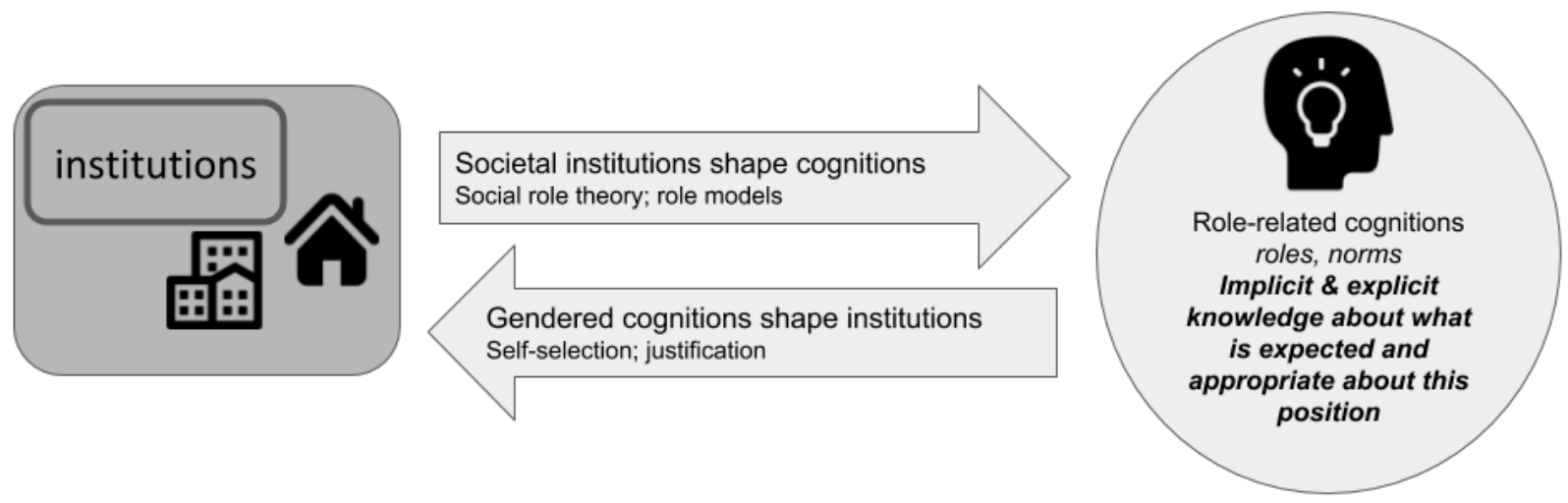

\section{Social Structure Creates Gendered Cognitions}

Individuals observe women and men occupying certain positions in the social structure, and in turn enacting certain behaviors. From this observation, they infer that each gender group possesses the traits cued by those behaviors (correspondent inference; Gilbert \& Malone, 1995), leading to gender stereotypes (Eagly et al., 2000; Eagly \& Wood, 2011). Individuals observe the gendered division of labor, in which women hold responsibility for caregiving and men hold positions of leadership or economic provision. Observers then form impressions that align the social category of women with the characteristics required to care for others - namely, communal characteristics. In parallel, they form 
impressions that align the social category of men with the characteristics displayed when one enacts leadership - namely, agentic characteristics. Individuals infer group-stereotypic traits from information about the occupational or family roles associated with the group (Eagly \& Steffen, 1984; Koenig \& Eagly, 2014).

The reality that men and women are closely allied across a range of contexts, including families as well as workplaces, leads cognitions about gender groups to diverge from other intergroup cognitions. The evaluative content of stereotypes about women tends to be positive, owing to the strong communal stereotypes, leading to a "women are wonderful" effect (Eagly et al., 1991; Eagly \& Mladinic, 1989; Rudman \& Goodwin, 2004). Yet these seemingly positive beliefs and attitudes are not always positive in their outcomes. According to ambivalent sexism theory (Glick \& Fiske, 2001), these subjectively positive beliefs function alongside more negative beliefs to perpetuate gender inequality. Thus, women can be simultaneously viewed as undeserving of equal outcomes in the workplace at the same time that they are held up as morally superior to men. Similarly, the stereotype content model holds that beliefs about groups include two dimensions of warmth and competence that emerge from status and cooperative relationships between groups (Cuddy et al., 2008; Fiske et al., 2002). In this model, groups with higher power tend to be perceived as more competent than groups with lower power. Groups that exist in cooperative relationships tend to have stereotypes that include warmth. Given this, the content of stereotypes of women and men depends on specific subtypes: Traditional women who accept having lower status and support men's agency are perceived as warm but not especially competent, whereas feminists or "career women" who advance their own interests and compete against men for positions of power are perceived as higher in competence but lower in warmth.

As the positioning of women and men in the social structure shifts across time and culture, so too do gender cognitions. As women in the U.S. in the late $20^{\text {th }}$ century entered roles once predominantly occupied by men, some aspects of gender stereotypes shifted. For example, public opinion data increasingly endorsed beliefs that women are competent (Eagly et al., 2019). These attributes align with the movement of women into the paid labor force, into higher education, and into higher visibility leadership roles. The presence of female exemplars in leadership roles produces implicit gender cognitions that associate women with leadership (relative to supportive roles) in both experimental and naturalistic studies (Dasgupta \& Asgari, 2004). For example, 2017 marked the first time that the majority of Gallup poll respondents reported no preference for a man as their boss (Brenan, 2017). Yet the positioning of women and men in the social structure continues to diverge, particularly in women's continued responsibility for caregiving both in domestic work and in health and education occupations (Croft et al., 2015). Even within male-dominated professions, women tend to specialize in more care-oriented activities than do men: For example, female professors engage in more service work than their male colleagues (Guarino \& Borden, 2017), female physicians tend to spend more time communicating with patients (Hall et al., 1994), and female STEM faculty tend to occupy more teaching-intensive positions than research-intensive positions (Eagly, 2020). Consistent with this stable focus on care along with greater visibility of women's roles, US public opinion data show persistent and growing beliefs that women are more communal than are men (Eagly et al., 2019). Communality may thus be the current hallmark of differentiated expectations about gender in the 
United States, whereas the gender gaps related to intelligence or competence have narrowed over the past half century.

Gender roles also vary across culture. Across cultures, men are viewed as having more status than women, given their roles as economic providers and societal leaders. However, these patterns of gender differences in status are believed to vary as a function of cultural evolutionary forces. For example, modern gender role attitudes can be traced to cultural variation in whether local economies depended on the plough (Alesina et al., 2013). In geographic regions where the plough was a key agricultural tool, men's greater size and upper body strength (and thus unique physical ability to work in the fields) led to a greater gendered division of labor. These early differences, tied to pre-industrial economic drivers, are echoed in country level variation today: Countries that adopted the plough centuries ago have greater gender inequality in labor force participation and leadership and also hold attitudes that justify these inequalities (Alesina et al., 2013).

Given men's higher status in most societies, the traits and roles associated with men (or any higher status group) are often assumed to have more utility (Schmader et al., 2001). For that reason, people are generally more supportive of efforts to encourage women to enter into domains dominated by men than they are to encourage men to enter into domains dominated by women (Block et al., 2019). In Western industrialized societies, communal roles are perceived as having less worth to society, especially by men who themselves place less value on being communal (Block et al., 2018). However, the same might not be true in all cultural contexts. Some research finds that in collectivistic cultures, the dominant ideology for harmony and communion means that it is considered normative to prioritize concern for others over self-interest. Perhaps as a result, being communal is viewed as less stereotypically feminine in collectivist cultures like South Korea (Cuddy et al., 2015).

Merely observing an unequal representation of women or men in a role influences beliefs about the groups represented as well as what the role entails. For example, both experimental and longitudinal studies have found that exposure to women in leadership positions bolsters implicit associations between the category of women and leadership characteristics (Dasgupta \& Asgari, 2004). Furthermore, role models in the field (both male and female) foster women's own expectation of success if they challenge the "geeky masculinity" stereotypes associated with computer science (Cheryan et al., 2011). Similarly, scientists (regardless of their gender) who are described as integrating collaborative work elevate women's interest in pursuing science careers by changing perceived communal affordances of the scientist role (E. K. Clark et al., 2016; Fuesting \& Diekman, 2017). Finally, when men learn that male peers value communal attributes and see them as congruent with being agentic, they are more willing to describe themselves in communal ways and to express preferences for communal activities (Van Grootel et al., 2018).

\section{Impact of Gendered Cognitions on Social Institutions}

Societal structures not only shape the nature of gendered cognitions, but those gendered cognitions then have a reciprocal relationship in maintaining gendered institutions. Most notable, the existence and endorsement of gendered cognitions about appropriate role behavior - particularly beliefs that women are and should be communal, whereas men are and should be agentic - shape who enters into, advances, and holds power in different societal institutions. 
Selection into contexts and roles. Any societal institution is constituted by individuals who identify and express gender; these individual-level behaviors to enter, persist, or exit certain institutional roles arise from beliefs about who is appropriate for particular roles. Role congruity processes (Eagly \& Karau, 2002) describe how individuals who violate role expectations are denigrated, whereas individuals who fulfill role expectations are valorized. We detail more about gender stereotype confirmation and violation in the next section (Interpersonal Interactions).

The constitution of societal institutions is also influenced by gendered cognitions related to the self: Gendered identity and expression can influence whether entry into particular roles is attractive or unattractive; what appears as a "choice" can be the result of accumulating channeling or constraint sometimes in overt or direct ways, and sometimes in subtle and indirect ways. Yet gendered views of the self certainly influence how individuals engage with societal institutions: Individuals may perceive some roles as more or less attractive, given their gender socialization around agency or communality. How individuals navigate the social structure is thus an outcome of both internalized and externalized forces (Diekman et al., in press).

As individuals consider approaching or avoiding different roles, they are guided by the implicit or explicit sense that their individual qualities will align with the features of the specific environment or broader field. For example, highly male-dominated fields such as computer science can signal a lack of belonging to women because of the stereotypes about the role (Cheryan et al., 2017). In experimental research, presenting computer science spaces as stereotypical (or not) depressed young women's but not young men's interest in majoring in computer science (Cheryan et al., 2009; Master et al., 2016).

How individuals perceive specific contexts as fitting with different self-aspects is the key question underling the State Authenticity as Fit to Environment (SAFE) framework (Schmader \& Sedikides, 2018). Self-concept fit assesses whether the environment allows for one's true self; goal fit assesses whether personal values and goals are afforded; social fit assess whether the context signals validation from others. Societal institutions and specific contexts can thus signal whether the particular attributes of an individual will be valued, and whether an individual will be able to pursue the goals that they value. In particular, roles are perceived to vary in their affordances for goal pursuit, and these perceived and actual affordances play a role in gender disparities in some fields. For example, STEM fields are often perceived as lacking communal opportunities to work with or help others (Diekman et al., 2017). Gender gaps in STEM interest can be partially explained by taking into account genderdifferentiated communal goal endorsement (Diekman et al., 2010). When communal opportunities in STEM are highlighted, gender gaps in STEM interest narrow (Diekman et al., 2011; Steinberg \& Diekman, 2018). The goal congruity perspective highlights that expectancies about the societal structure or context, as well as attributes encoded in the self, are key to understanding role navigation.

\section{Perpetuation and justification of traditional roles.}

People are motivated to justify the existing system, even if this justification incurs personal or group-level costs (Jost et al., 2004; Jost \& Banaji, 1994). The beliefs that men and women possess complementary traits that equip them for their roles can also justify existing systems of gender inequality (Brescoll et al., 2013; Jost \& Kay, 2005). The content of gender stereotypes justifies the roles each gender is thought to be suited for: The belief that men are more agentic supports the belief that men should be breadwinners and leaders; the belief that women are caring and moral supports the 
belief that they should provide direct caregiving. Yet in addition, beliefs that male and female genders are complementary supports the traditional division of labor: The ability to ascribe different but positive traits to the other gender supports endorsement of gender stereotypes. The mere presence of complementary gender stereotypes can foster contentment with the status quo (Jost \& Kay, 2005).

\section{Interpersonal Perceptions and Interactions}

Gender is embedded and experienced in social interactions. These interactions translate the unequal representation and status at the societal level to individual experience and reactions. When gender is embedded in societal institutions (such as work or family), gender then becomes embedded in contexts, shapes social perceptions, and is transmitted to individuals through specific interactions. For example, occupational gender segregation reflects a societal level construct, whereas an individual's experience of occupational gender segregation will occur through how they are perceived and treated in educational contexts or workplaces. In this section, we first examine how interpersonal interactions foster gendered cognitions (top arrow of Figure 4) and then elaborate how gender cognitions shape social perception and interaction.

Figure 4 Interpersonal Interactions/Perceptions and Gendered Cognitions: Reciprocal Pathways
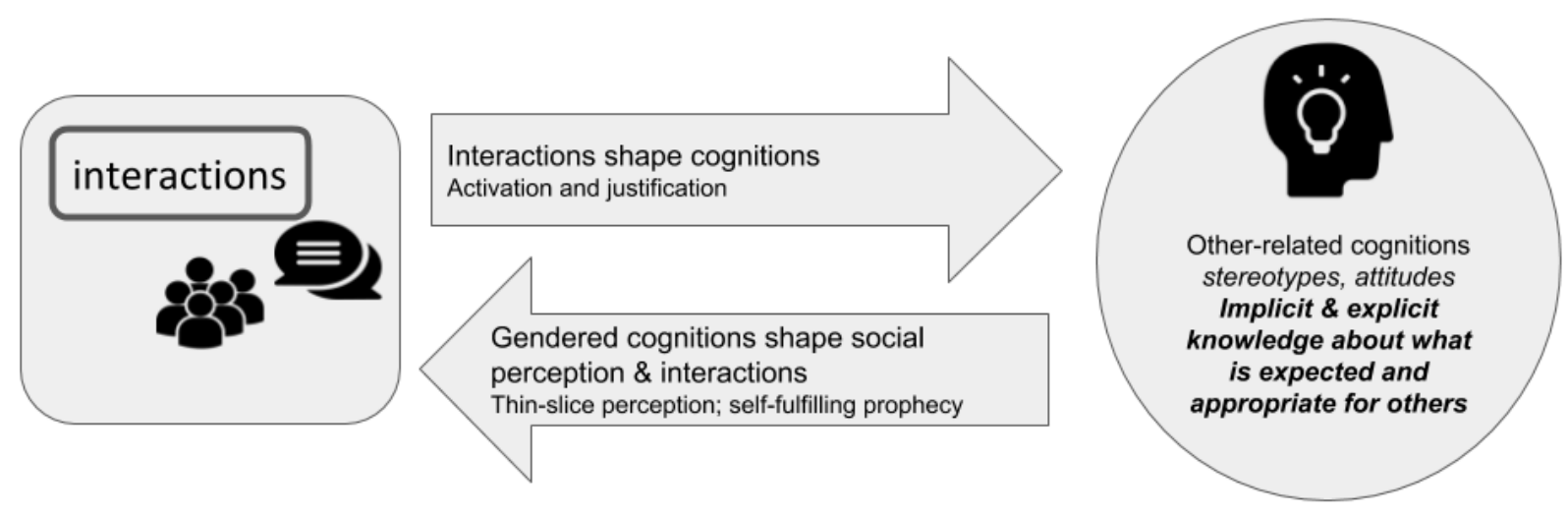

\section{Social Contexts Can Activate and Justify Gendered Cognitions}

Specific contexts provide cues about whether gender is used as an organizing principle. When gendered cognitions are activated in a given context, they can also affect how women and men perceive and behave toward one another in a dynamic interaction process (Deaux \& Major, 1987). The differential salience of gender in each actor's cognitions and behavior can make gendered behavior more or less likely. The chronic presence of contextual cues to gender in a given domain can perpetuate the use of gender in decision making and social interactions. In this way, the perpetuation of gender biases can be usefully reconsidered as a property of a place, rather than as the property of individuals (Murphy \& Walton, 2013). One cue to whether gender is important within a context is numerical representation: When a gender group is overrepresented, gender categorization is likely to be more salient, and the overrepresented gender is perceived as the default (Cheryan \& Markus, 2020).

Within specific contexts, individuals also cue gendered cognitions through their own gender expression. For both cisgender and transgender individuals, gender can be expressed through dress, actions, or explicit statements. Although one's gender expression often adheres to the norms for one's gender (e.g., someone might identify as female and show typically feminine dress and interests), it can 
also diverge from those norms (e.g., someone might identify as female and show typically masculine interests and not strongly gendered dress). Furthermore, individuals might also flexibly adapt their expression to signal their identity to others (Lick et al., 2013).

Social contexts can also support gender cognitions through meta-cognitive processes of justification and validation. When individuals are able to justify their stereotypic expectations, they are more confident in these expectations, and these beliefs exert greater impact on decision making (J. K. Clark et al., 2017). We elaborate these confirmation processes further below; here we note that contexts not only provide activation of gendered cognitions but also provide the apparent "evidence" by which these expectations gain greater rigidity and impact.

\section{Impact of Gender Cognitions on Social Perceptions}

Stereotyping in thin slice perception. Stereotypes, once activated, create hypotheses about a person's actions, attitudes, interests, and abilities (Darley \& Gross, 1983; Fiedler \& Walther, 2004). Thus, when situations make gender relevant, gender stereotypes have the potential to bias judgment. This can happen based on minimal, thin-slice, information including facial features, body shape, hair style, voice, and movement (e.g., K. L. Johnson \& Tassinary, 2016). For example, the facial features used to perceive a person as competent are more closely connected to male than to female faces (Oh et al., 2019). Such associations likely feed into broader stereotypes associating men more than women with brilliance (Bian et al., 2018). Although some people might explicitly hold and endorse these stereotypes, often they are encoded as implicit associations between these traits and gender that are distinct from people's explicit beliefs (Nosek et al., 2002; Rudman et al., 2001; Rudman \& Goodwin, 2004).

The tendency to associate women with communion and men with agency (particularly brilliance or dominance) can affect how women and men are perceived and the outcomes they receive. These effects appear to be most pronounced when someone is being judged in a domain where their gender is negatively stereotyped or otherwise underrepresented and when qualifications are at least somewhat ambiguous (Eagly \& Karau, 2002; Heilman, 1983). For example, when evaluating an application for a research position in a science lab, both men and women scientists more favorably evaluate a candidate with a male than a female name (Moss-Racusin et al., 2012). Women who succeed in male-dominated occupations incur penalties for their assumed lack of communality; when explicit information about communality is available, such women do not face penalties on likability (Heilman \& Okimoto, 2007).

Stereotyping is not inevitable. The research on gender stereotyping by no means suggests that these effects are inevitable. Indeed, a number of factors can disrupt stereotyping processes. First, consistent with social structural roots of stereotypes, the content of gender stereotypes varies across time and culture. For example, the implicit tendency to associate science more with men than with women has been weakening over time, as observed in patterns of science $=$ male implicit associations measured in almost two decades of data from the Project Implicit website (Charlesworth \& Banaji, 2019), as well as in children's increasing tendency over the past seven decades to draw a scientist as a woman (Miller et al., 2018). Furthermore, variation in these associations across culture (Miller et al., 2015; Nosek et al., 2009) suggests that not all cultures possess these particular gender stereotypes and thus would not be likely to show stereotypic biases against women in the sciences.

Second, standard dual process accounts of stereotyping assume that even when people possess stereotypic associations with a group, those associations do not necessarily get activated or applied 
when evaluating a target (Crandall \& Eshleman, 2003; Devine, 1989; Fazio \& Towles-Schwen, 1999). In terms of activation, dynamic models of stereotyping assume that even if a category is salient initially, that activation might dissipate as one gains more individuating information about a target (Kunda et al., 2002; Neuberg \& Fiske, 1987). However, stereotypes can also be reactivated by later information that seems to justify using those stereotypes as an explanation for surprising negative outcomes (Sinclair \& Kunda, 2000). For example, perceivers confer status to both male and female leaders regardless of whether they are in a gender-congruent or incongruent context. But leaders who make a mistake more easily lose status when leading in a gender-incongruent context, whether these leaders are women or are men (e.g., male president of a women's college; Brescoll et al., 2010).

Even when stereotypes are activated, perceivers can control whether those beliefs bias their judgment. For example, those with a strong motivation to respond without sexism (Klonis et al., 2005) might suppress the degree to which gender stereotypes bias their judgment. However, breaking the link between activation and application requires that perceivers are aware that their judgments might be biased, are motivated to be less biased, and have the time and mental energy to control these automatic tendencies to fall back on stereotypes. Recent evidence suggests that interventions designed to raise awareness and motivation as well as provide people with strategies to control their biases are somewhat effective. When faculty members were trained to recognize their implicit biases and given tips on how to set them aside, they not only become more motivated to do so but actually hired (marginally) more women into their science departments over the next two years (Carnes et al., 2012, 2015; Forscher et al., 2017). Some evidence suggests that when choosing among highly qualified candidates, science faculty prefer hiring highly-qualified women over similar male counterparts (Ceci \& Williams, 2015; W. M. Williams \& Ceci, 2015).

Finally, these examples of how gender cognitions affect decision-making in real world contexts reflect that perceivers do not act in isolation. Rather, the norms of the local context influence the degree to which gender is salient, stereotypes are activated, and perceivers feel justified in applying them. Consistent with the bias of crowds perspective (Payne et al., 2017), understanding how implicit bias varies across environments, rather than just across individuals, holds promise for predicting how certain environments are more likely to activate and justify gendered cognitions. Such frameworks highlight the connections between norms that are created and reinforced at the institutional level and how individuals perceive and interact with one another. Even when individuals do not hold gender stereotypes personally, they might still apply broader cultural stereotypes in their hiring decisions to satisfy what they perceive to be the attitudes of others (Vial et al., 2019). Furthermore, in actual decision making contexts, the average implicit gender stereotypes of decision-making groups do not necessarily lead to biased decisions if those groups also believe that bias could be a problem (Régner et al., 2019). Thus, gender inclusive cultural norms have the potential to create contextual cues that make gendered cognitions less relevant to how people perceive each other.

\section{Impact of Gender Cognitions on Interpersonal Interactions}

Stereotype confirmation. People's perceptions are more than just their first impressions; often social perception happens during dynamic interpersonal interactions. In Deaux and Major's (1987) interactional model of gender, each actor in a dyadic interaction comes to the table with their own gender schemas and expectancies. Further, gender is a salient cue in some contexts but a less salient 
cue in other contexts. Based on these intrapersonal, interpersonal, and contextual inputs, each actor then acts and reacts in ways that perpetuate - or disconfirm - gender-stereotypic expectancies.

Self-fulfilling prophecies can occur when perceivers' gender stereotypic expectances change their behaviors in ways that elicit (and thus seemingly confirm) a stereotypic response from targets (Geis, 1993; Snyder, 1992). In a classic study illustrating gendered division of labor (Skrypnek \& Snyder, 1982), participants were asked to assign tasks to different group members, knowing that they had been provided randomly assigned profiles of each person that might or might not accurately reflect the person's gender. Nevertheless, task partners labeled as "male" were assigned to more male-stereotypic tasks, and task partners labeled as "female" were assigned to more female-stereotypic tasks.

These same effects are found in the division of transactive memory (Hollingshead \& Fraidin, 2003). Partners who were presumed to be female were disproportionately assigned to learn information about the stereotypically feminine categories (i.e., cosmetics, soap), whereas partners presumed to be male were disproportionately assigned to learn information about stereotypically masculine categories (i.e., cars, sports). These effects were more pronounced in cross-gender than in same-gender pairs suggesting that the composition and cues in the context amplify the use of gender as an organizing cue. Self-fulfilling prophecy effects accumulate when multiple people constrain one's choices based on gender stereotypic assumptions of one's preferences (Madon et al., 2018).

Individual actors can control their own expression of gender as a way to manage how they are perceived by others. Women majoring in male-dominated fields for example, report dressing in a less feminine way on days they have classes in their majors (Pronin et al., 2004). In this way, targets of stereotypes try to control the degree to which gendered cognitions are activated and likely to affect their interactions with men in their classes.

Self-fulfilling prophecies can subtly shape targets' behavior to confirm stereotypes. In one set of studies, when women and men were paired together to work on an engineering task, women paired with men who held more implicit gender stereotypes ultimately performed worse on a subsequent test of their own engineering ability (Logel et al., 2009). This effect of his stereotypes on her performance was mediated (as shown both statistically and experimentally) by these men's more dominant and flirtatious behaviors that women in these interactions did not dislike or label as sexist. In other research, women who were especially conscious about being the target of sexism treated men in ways that led them to act in a more hostile way toward the women (Pinel, 2002). In this work, women high in stigma consciousness were more critical of a man if they had some (erroneous) belief he might be sexist; he was then more likely to respond in a hostile manner that seemed to confirm her stereotype.

It is important to note that these self-fulfilling prophecy effects on behavior are not inevitable (Jussim, 2012). However, they demonstrate that when gender is made salient in social interactions, and perceivers feel justified in acting on those stereotypes, gendered cognitions play a role in shaping the context for each actor and eliciting behavior. These processes, amplified across perceivers, contexts, and time, create strong social scripts that reinforce gendered roles and norms, as well as gendered understandings of the self.

Backlash. When individuals act in counterstereotypic ways, activated stereotypes in the minds of perceivers can maintain the status quo by punishing people who violate those expectations. These anticipated and experienced negative repercussions constitute backlash (Rudman et al., 2012). For 
example, in experimental settings (Rudman \& Fairchild, 2004), participants are more likely to sabotage the efforts of individuals who deviate from gender norms. In their role prioritization model, Haines and Stroessner (2019) argue that both men and women are penalized when they are seen as deprioritizing their traditional gender role, though they can avoid this backlash if they seem to strike a balance between agentic and communal behaviors.

Indeed, several studies find evidence of backlash against agentic women in business and political contexts, especially when women engage in highly dominant or status-seeking behaviors (Okimoto \& Brescoll, 2010; Rudman et al., 2012). For example, the preference for gender-typical targets can affect a female political candidate's electability, particularly among more conservative constituents (Hehman et al., 2014). Women who explicitly seek status, not merely by being competent but by being dominant, are seen as less warm (M. J. Williams \& Tiedens, 2016). Similar effects appear even in thin slice perceptions of faces where women (but not men) with more dominant features are assumed to be less trustworthy (Oh et al., 2019; Sutherland et al., 2015). It is worth underscoring, however, that the intersectional nature of gender stereotypes means that backlash might manifest differently for women of different ethnic backgrounds: For example, Black women may be less likely than White or Asian women to be penalized for dominant behavior, given stereotypic expectations of dominance for Black women (Rosette et al., 2016).

Men also face backlash for deviating from male gender roles. For example, male elementary school teachers are rated as less likeable and a greater threat to safety than their female peers (MossRacusin \& Johnson, 2016). Men can also face backlash for failing to be dominant and assertive (MossRacusin et al., 2010). Backlash against gender atypical men has been found to be higher in more gender traditional societies (Kosakowska-Berezecka et al., 2018). In addition, heterosexual men whose own masculinity is threatened are more likely to exhibit backlash against gender atypical men (Glick et al., 2007) and even become vigilant to perceiving and remembering gender atypical male faces (Lick et al., 2014).

Because both women and men are aware of potential backlash, they often vary their gender expression to manage their impression in interpersonal contexts. For example, women's fear of backlash can keep them from self-promoting (Moss-Racusin \& Rudman, 2010), even though they do not show the same concern when promoting others (Amanatullah \& Morris, 2010). Or women who are agentic might learn to temper their dominance behaviors with expressions of care and warmth (Bauer, 2017; Rudman \& Glick, 2001). In a related way, heterosexual men also act more aggressively if they are concerned that others might question their sexual orientation or gender identity (Vandello et al., 2008), and men who are concerned about their manhood being questioned are less likely to stand up against anti-gay prejudice (Kroeper et al., 2014). Individuals who are experimentally induced to violate gender norms anticipate backlash from others and adjust their cognitions and behaviors to reinstate gender norms (Rudman \& Fairchild, 2004).

An essential point is that when gender is embedded in social interactions it does not only yield gendered expectations but also leads to gendered experiences. Individuals who repeatedly engage in social interactions in which others treat them as powerful, independent, and authoritative will practice different skills and be introduced to different opportunities than others. A different reality will emerge for those who are consistently treated as kind, nurturing, and subservient. As we detail in the next 
section, these different expectations, experiences, skills, and opportunities become encoded into aspects of the self.

\section{Individual-Level Processes}

As individuals encounter gender at the institutional and interpersonal levels, they also incorporate gendered cognitions into their own sense of self. From an early age, gender is an organizing feature for self-related information, as children learn and come to see themselves in relation to gender binary categories (Bussey \& Bandura, 1999). The self is an active agent in creating gender: Information about stereotypes and roles inform aspects of the self, and the individual in turn acts within specific interactions and to influence societal institutions. Following Figure 5, we examine how individual-level processes give rise to gendered cognitions (top arrow), and then examine how gendered cognitions influence what is integrated into the self.

Figure 5 Individual-Level Processes and Gendered Cognitions: Reciprocal Pathways
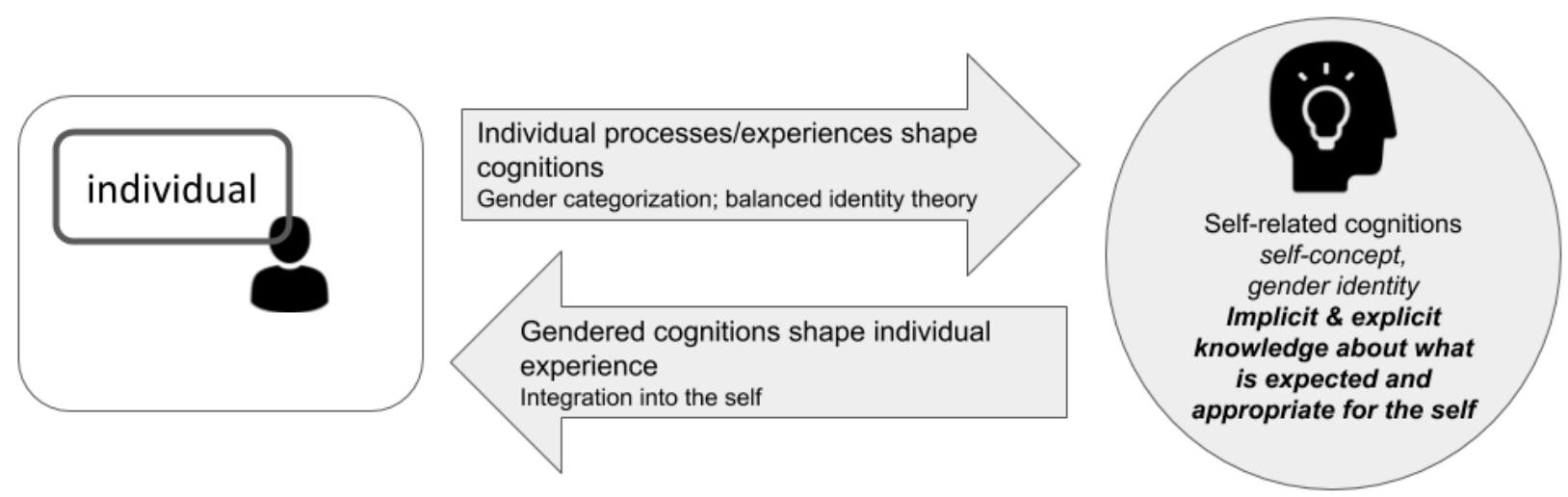

\section{Individual processes and experiences create gendered cognitions}

Gender categorization. From an early age, children not only categorize others but also categorize themselves as being either female or male (Maccoby \& Jacklin, 1974). Increasingly, psychological science recognizes that some individuals do not see their own identity as fitting within the gender binary (Hyde et al., 2019); yet the prominence of the gender binary both stems from and contributes to the vast of majority of people who explicitly identify as women or men. Explicit gender identification correlates highly with one's implicit tendency to associate that gender with the self (Block \& Schmader, 2020). This correspondence between implicit gender and explicit gender identity is even found among transgender children who show a stronger implicit self-association to their expressed gender identity than to the sex classification they were assigned at birth (K. R. Olson et al., 2015). Thus, once individuals categorize themselves in a gender binary, that gender label becomes implicitly and explicitly connected to identity. Those who are transgender or closely identify with transgender individuals have a greater appreciation for the malleability of gender and weaker tendency to apply gender stereotypes (Fast \& Olson, 2018; Olson \& Enright, 2017). However, despite the increasing prevalence of more fluid understandings of gender, there remains a strong tendency to view gender to be an essentialized feature of oneself and others (Gelman et al., 1986; Gelman \& Gelman, 2003; Roberts et al., 2017), even in highly gender egalitarian cultures such as Sweden (Klysing, 2020). 
Balanced identity theory. Once a person has categorized themselves as a boy or a girl, the stereotypes that have become attached to those gender categories tend to be automatically applied to one's own self-definition. From a social cognitive perspective, balanced identity theory provides a key framework for how stereotypes become internalized (Cvencek et al., 2012). Extending Heider's (1958) foundational research on balanced cognitions, balanced identity theory argues that one's own concept of self can also be shaped, even implicitly, by the ways in which identity-relevant concepts cohere into logically consistent triads. These triads are formed by the implicit associations one has between their concepts of self, a group identity, and a domain. In the typical formation, if self = group $A$, and group $A=$ domain $\mathrm{Y}$, then self $=\operatorname{domain} \mathrm{Y}$; but if $\operatorname{self}=\operatorname{group} \mathrm{B}$, and group $\mathrm{A}=\operatorname{domain} \mathrm{Y}$, then self $\neq$ domain $\mathrm{Y}$.

Balanced identity theory has most typically been applied to examine the formation of implicit self-stereotypes (Cvencek et al., 2020) (Cvencek et al., 2020). For example, women's tendency to implicitly associate math more with men than women relates to women's tendency to associate math less with themselves (Nosek et al., 2002). Furthermore, women who do not strongly identify with their gender and who have weak implicit gender stereotypes perform better on tests of their math ability. These same kind of stereotypic constraints on self-definition have been observed in children. The degree to which elementary school-aged girls implicitly associate themselves with the concept of female (vs. male), but implicitly associate the concept of male (more than female) with math, predicts the degree to which girls exhibit a weaker association of the self with math (Cvencek et al., 2014).

The core assumption underlying balanced identity theory is that the human mind's preference for consistency sets in motion a tendency to implicitly self-stereotype to the degree that one identifies with a gender category that has associated stereotypes. If the stereotypic association to the group is not strong, then one is less likely to internalize this stereotypic association. For example, among a sample of men and women, those who do not differentially associate communion with women show no gender differences in self-associations with communion (Block \& Schmader, 2020). Furthermore, experimentally retraining an association of communal = male increases men's tendency to associate communion with their own self-concept. Following a similar logic, implicit gender/math stereotypes are weaker among Black than White female adolescents, consistent with smaller gender gaps in STEM interest among Black women (O’Brien et al., 2015).

Balanced identity theory explains how basic cognitive associative processes can lead people to internalize gendered views of themselves, even in the absence of explicit or intentional processes of gender socialization. In fact, one might hold stereotypical self-associations that are distinct from one's explicit desire to see oneself as counterstereotypical. For example, even women who have chosen a career or major in science and are thus highly invested in these domains, show gendered identity patterns. The tendency to implicitly link maleness to science predicts women's own self-views, feelings of fit, and commitment to their career choice (Block et al., 2018; Nosek et al., 2002). Understanding gender cognitions as embedded within the broader context, and not solely within the self, provides a useful lens to understand this phenomenon.

One example of the interplay between broader context and the self is found in the effects of exemplars in roles on individual-level beliefs and attitudes toward different roles. Exposure to successful female role models in typically male-dominated fields can change gendered self-views. According to the stereotype inoculation model (Dasgupta, 2011), women's self-efficacy in stereotypically male-dominated 
domains can be boosted by their exposure to successful female role models. Exposure to successful women in STEM increases women's positive attitudes toward, self-efficacy in, and motivation for STEM, whether assessed experimentally or in naturalistic education settings (Stout et al., 2011). Further, among Black and Latina women, who are underrepresented in science by both gender and race, seeing STEM exemplars who share their intersectional identity can be particularly important (I. R. Johnson et al., 2019; Pietri et al., 2019).

\section{Impact of gender cognitions on individual-level processes: What aspects become integrated into the self?}

We first note that processes describing how gendered self-cognitions shape individual experience have been reviewed earlier in this chapter. Gendered self-concept or motives, for example, can influence entry into particular roles and environments (Diekman et al., 2017; Schmader \& Sedikides, 2018), and influence dynamic social interaction (Deaux \& Major, 1987). Here, we turn to a different question of how the embeddedness of gender can elucidate how gendered cognitions become integrated into the self. First, people might be more willing to internalize gender expectations that present themselves in a positive light (Rudman et al., 2001). For example, from an early age, both girls and boys exhibit more positive implicit attitudes about their own gender (Dunham et al., 2016). Over time, this positive ingroup bias becomes especially strong for girls and women (Rudman \& Goodwin, 2004), perhaps because the female gender is stereotypically associated with positive traits such as warmth and communion.

Second, the perceived status of attributes associated with men versus women can lead to differential internalization of gender stereotypes. As discussed above, in many cultures and subcultures, a status asymmetry exists whereby the traits and domains associated with men are accorded higher status than those associated with women (Croft et al., 2015; Ridgeway, 1992). As a result, women are more motivated to embrace attributes and domains connected to men more than men are motivated to embrace attributes and domains connected to women (Schmader et al., 2001). In one study, men had no interest in possessing a trait called surgency if they learned that women were higher than men on this trait. However, women personally valued the trait if men scored higher than women. The association of surgency with men, a higher status group, led them to infer that the trait might be useful for career success.

Third, people might be more likely to internalize stereotypes that align with their idiosyncratic traits. Men who have more dominant-looking faces, for example, might be more likely to internalize the stereotype that men are more dominant. After all, their personal experience seems to justify the stereotype. For example, individual differences in digit ratio, as a physical measure of early androgen exposure, correlate with (especially men's) implicit stereotypic associations (Schmukle et al., 2007). Although this research was carried out on a small sample, the suggestion is that men exposed to greater testosterone in the womb develop stronger gender stereotypes. Whether this occurs through biological or sociocultural pathways, or a mixture of the two, is not yet clear. Social and biological processes generally intertwine to create, perpetuate, and challenge the sex/gender binary (Hyde et al., 2019). Nonetheless, we might assume that those who believe that gendered categorizations are more arbitrary, overlapping, or malleable, might also be less likely to see the self in gendered ways (Block \& Schmader, 2020). 


\section{Implications of Gender as Embedded Cognition}

Understanding gender as embedded cognition allows for an examination of how cognitions at these different levels reinforce each other. As illustrative examples, we review how individual-level differences in social cognition are shaped by and shape interactions and engagement with institutions, and we examine potential malleability at each level.

\section{Gender differences and similarities in social perception}

The framework we have delineated here examines the social cognitive processes about gender that shape perceptions of the self, others, and social roles. This review has been guided by a definition of social cognition that focuses on the application of cognitive methods and theories to understand social processes. But social cognition can also refer more specifically to the ability to perceive and think about other people - that is, as synonymous with social perception. When viewing the topic of social cognition through this lens, there is a distinct but interesting question of whether gender shapes social perception. The set of gender embedded processes we have described has implications for how gender at the level of the individual influences interactions with others and how one navigates the social structure. Although a full review of the causes of sex differences in social cognition is beyond the scope of this chapter, here we examine gender differences in social perception accuracy through the lens of gender as embedded cognition. From an embeddedness perspective, we ask whether any differences or similarities in social perception might be explained by differential expectations and experiences of women and men in self-views, in social interaction, and in societal institutions.

As reviewed above, the distribution of men and women into different roles leads people to assume that men are more agentic (justifying their roles as breadwinners and leaders), whereas women are more communal (justifying their roles as caregivers at home and in the labor force). The assumption that women are more socially and communally oriented is often justified by evidence of women's superior social sensitivity, emotional intelligence, and empathy. For example, Baron-Cohen and Wheelwright (2004) describe empathizing, the tendency to spontaneously tune into others' thoughts and feelings, as the core skill of the "female brain" and argue that women, on average, have a clear advantage in these abilities. Fine (2010) counters that such biologically essentialized views of these abilities are not justified by the evidence and contribute to the perpetuation of stereotypes.

The ability to tell what others are feeling is sometimes labeled empathic accuracy or social sensitivity. Older studies of empathic accuracy often report quite large gender differences that advantage women (e.g., Eisenberg \& Lennon, 1983). However, one meta-analysis (Ickes et al., 2000) discovered that the gender difference was only observed in studies where participants were aware that their ability to empathize was being evaluated or that gender was otherwise made salient (see also Klein \& Hodges, 2001). When the task was described more neutrally, men performed as well as women. In a similar vein, other research has shown that men perform more poorly on measures of social sensitivity or emotional understanding when reminded of stereotypes that advantage women in these arenas (Koenig \& Eagly, 2005; Leyens et al., 2000). Contextual cues that gender is important in social interaction thus promote gender differences in social perception.

In recent years, measures of the empathic accuracy have been replaced with tasks purported to assess theory of mind capabilities - the ability to accurately read what others might be thinking. The Mind in the Eyes task (Baron-Cohen et al., 2001) has been used extensively as a behavioral measure of 
emotional accuracy or theory of mind. A meta-analysis of gender differences on this measure reveals differences that are small to moderate (Kirkland et al., 2013). Yet performance on this task is also affected by contextual cues. The gender difference was eliminated and in some cases even reversed when incentivized financially (Ridinger \& McBride, 2015). This evidence suggests that men's lower performance on measures of theory of mind might be influenced by their constraints and opportunities within particular situations. Men's lower performance on tasks related to social perception may have more to do with men's lower motivation to attend to others than any innate ability.

Understanding gender as an embedded process that is elaborated in cognition helps us understand why men might be less motivated to attend to and understand others' thoughts and feelings. First, the roles that focus on caregiving and orientation toward others tend to be strongly female-dominated: Men are less likely to engage with and identify with communal roles and activities as a result of the longstanding stereotypes that associate communion with women and thus with lower status (Croft et al., 2015). Indeed, if anything, the association between women and communality getting stronger over time in the United States (Eagly et al., 2019). These stereotypes, through balanced identity processes, can contribute to how men (perhaps from an early age) develop a weaker association of communal orientations with themselves (Block \& Schmader, 2020).

It is clear from the data that beliefs about gender differences in social sensitivity tend to be larger than actual gender differences in social sensitivity. This discrepancy was recently documented in a series of studies (Eyal \& Epley, 2017) showing that whereas performance differences between men and women on three different measures of empathic accuracy were small to nonexistent (in modestly sized samples), people expected those differences to be very large. In research on accuracy in forming first impressions, research also finds no substantial evidence of a female advantage on the ability to quickly ascertain the profile of personality traits that distinguishes a person from others (Chan et al., 2011). Although this research found that women might be somewhat more able to accurately guess what the average person is like, that advantage might simply be because women generally make more positive ratings of others than men do. In general, available evidence on actual performance differences suggests people generally expect men to be less socially skilled than they actually are capable of being. This expectation can itself set into motion gender-differentiated experiences and consequences (for example, greater self-disclosure to women than men in social interactions; Fehr, 2004).

\section{Malleability of Gender}

Understanding gender as produced through gendered cognitions embedded in the self, social interaction, and societal institutions yields a clearer view of the stability and malleability of gender. Put simply, recognizing embeddedness does not mean that gender is stagnant: Rather, recognizing embeddedness suggests that change in any one level will reverberate across the other levels.

As the gendered division of labor shifts, the content of gender stereotypes can also shift - at least to some extent. When perceivers are asked to imagine women or men of the past, present, or future, their ascriptions of traits align with the division of labor that they estimate for this time point. In particular, U.S. observers perceive women as gaining in masculine personality, cognitive, and physical characteristics, whereas they perceive men as remaining stable in their characteristics (Diekman \& Eagly, 2000; Diekman \& Goodfriend, 2006). As women's rates of paid employment increase across cultures, the stereotypes of women shift dynamically to include more agentic traits (Bosak et al., 2018). In some 
cases these changes have less to do with gender and more to do with country-level transitions to capitalism and democracy. For example, dynamic stereotypes in Latin America reflect increasing agency among men as well as women, given that both genders have experienced an increase in their economic and political independence (Diekman et al., 2005).

When the broader societal structure is perceived to shift, individuals respond in ways that accommodate those changes. When the occupational roles of one's gender group are described as shifting to become more nontraditional, individuals estimate that they will meet more success in gender-counterstereotypic occupations. In one study, men and women were randomly assigned to read ostensible news articles either about stability or change toward nontraditional roles for their gender group. For each group, those who received information about change for their group forecasted more success for themselves in counterstereotypic roles (Diekman et al., 2013). In this way, believing that gender norms in the future diverge from gender norms of today may lead people to develop less gender-stereotypic gender identities and gender expression (consistent with dynamic norm processes; Sparkman \& Walton, 2017).

Gendered cognitions also play a role in facilitating or slowing gender role change. Notably, the lay explanations that people have for gender inequalities predict their support for efforts aimed at changing the status quo (Block et al., 2019). People are relatively more supportive of efforts to desegregate male-dominated careers in STEM because they believe biases play a role in blocking women's opportunities; however, they express less interest in desegregating female-dominated communal careers because men are assumed to be uninterested in these lower status roles in the first place. These assumptions might then contribute to asymmetric changes in gendered divisions of labor.

Yet even in examples of accommodation, cultural beliefs about women and men can reflect "cultural lag" (Brinkman \& Brinkman, 1997). Given the complex nature of shifts in gender roles, beliefs and attitudes can include a mixture of those that accommodate or anticipate a new reality, as well as those that uphold traditional roles (Diekman et al., 2013; Diekman \& Goodfriend, 2006). Further, reverberation across levels does not always mean accommodation: Sometimes reverberation means resistance to gender disruptions. Motivated reasoning processes maintain existing beliefs. Thus, because gender stereotypes both reflect and justify the gender hierarchy, evidence of changing gender roles can promote a rebound effect, in which people hold even more tightly to traditional beliefs. As just one example, the hostile sexist belief that feminists are taking over men's roles is tightly linked to the benevolently sexist belief that women are uniquely suited to traditional caregiving roles (Glick \& Fiske, 2001). On an interpersonal level, making "gender trouble" by challenging the binary in terms of gender expression can elicit threat and hostility (Morgenroth \& Ryan, 2020). In sum, fluidity or malleability in any one of the levels described here will not produce more widespread fluidity or malleability unless echoed, amplified, and made real across these levels.

\section{Conclusions}

An embedded cognition perspective allows for a clearer delineation of the cognitive processes that arise from and contribute to gendered views of the self, gendered social interactions, and gendered societal institutions. As we noted earlier, this type of multilevel process might play out with other social categories; yet the gender binary is unique in how pervasive and accepted it is - and thus how integrated it is into institutional and interpersonal levels, not only in cognition but in structure, position, 
policy, and law. Further, understanding how biological influences intersect with gendered cognitive and cultural processes elaborated here holds promise for deepening understanding of how gender shapes identity and social perception.

The embeddedness framework can contribute to understanding both the opportunities and the challenges inherent in shifting gender roles and closing gender disparities. Gender - in its simple and complex processes - provides an essential site to understand cognition as not only within an individual's mind but as arising from and contributing to individual experience, social interaction, and societal institutions. 
References

Abele, A. E., \& Wojciszke, B. (2007). Agency and communion from the perspective of self versus others. Journal of Personality and Social Psychology, 93(5), 751-763. https://doi.org/10.1037/00223514.93.5.751

Alesina, A., Giuliano, P., \& Nunn, N. (2013). On the Origins of Gender Roles: Women and the Plough. The Quarterly Journal of Economics, 128(2), 469-530. https://doi.org/10.1093/qje/qjt005

Amanatullah, E. T., \& Morris, M. W. (2010). Negotiating Gender Roles: Gender Differences in Assertive Negotiating Are Mediated by Women's Fear of Backlash and Attenuated When Negotiating on Behalf of Others. Journal of Personality and Social Psychology; J Pers Soc Psychol. https://doi.org/10.1037/a0017094

Ashmore, R. D., \& Del Boca, F. K. (1981). Conceptual approaches to stereotypes and stereotyping. In Cognitive processes in stereotyping and intergroup behavior (pp. 1-35). Erlbaum.

Bailey, J. M., Vasey, P. L., Diamond, L. M., Breedlove, S. M., Vilain, E., \& Epprecht, M. (2016). Sexual Orientation, Controversy, and Science. Psychological Science in the Public Interest, 17(2), 45101. https://doi.org/10.1177/1529100616637616

Bakan, D. (1966). The duality of human existence: An essay on psychology and religion. Rand Mcnally.

Baron-Cohen, S., \& Wheelwright, S. (2004). The Empathy Quotient: An Investigation of Adults with Asperger Syndrome or High Functioning Autism, and Normal Sex Differences. Journal of Autism and Developmental Disorders, 34(2), 163-175. https://doi.org/10.1023/B:JADD.0000022607.19833.00

Baron-Cohen, S., Wheelwright, S., Hill, J., Raste, Y., \& Plumb, I. (2001). The "Reading the Mind in the Eyes" Test Revised Version: A Study with Normal Adults, and Adults with Asperger Syndrome or High-functioning Autism. The Journal of Child Psychology and Psychiatry and Allied Disciplines, 42(2), 241-251. https://doi.org/10.1017/S0021963001006643

Bauer, N. M. (2017). The Effects of Counterstereotypic Gender Strategies on Candidate Evaluations. Political Psychology, 38(2), 279-295. https://doi.org/10.1111/pops.12351

Bem, S. L. (1974). The measurement of psychological androgyny. Journal of Consulting and Clinical Psychology, Vol. 42, 155-162.

Berger, J., Wagner, D. G., \& Zelditch, M. (1985). Introduction: Expectation states theory: Review and assessment. In Status, rewards, and influence (pp. 1-72). Jossey-Bass Publishers.

Bian, L., Leslie, S.-J., Murphy, M. C., \& Cimpian, A. (2018). Messages about brilliance undermine women's interest in educational and professional opportunities. Journal of Experimental Social Psychology. https://doi.org/10.1016/j.jesp.2017.11.006

Block, K., Croft, A., De Souza, L., \& Schmader, T. (2019). Do people care if men don't care about caring? The asymmetry in support for changing gender roles. Journal of Experimental Social Psychology, 83, 112-131. https://doi.org/10.1016/j.jesp.2019.03.013

Block, K., Croft, A., \& Schmader, T. (2018). Worth Less?: Why Men (and Women) Devalue Care-Oriented Careers. Frontiers in Psychology, 9. https://doi.org/10.3389/fpsyg.2018.01353

Block, K., \& Schmader, T. (2020). Changing stereotypes, changing the self: Increasing communion by changing men's implicit gender stereotypes. (Invited revision of registered replication report at Journal of Experimental Social Psychology.). 
Bosak, J., Eagly, A., Diekman, A., \& Sczesny, S. (2018). Women and men of the past, present, and future: Evidence of dynamic gender stereotypes in Ghana. Journal of Cross-Cultural Psychology, 49(1), 115-129. https://doi.org/10.1177/0022022117738750

Brenan, M. (2017, November 16). Americans No Longer Prefer Male Boss to Female Boss. Gallup.Com. https://news.gallup.com/poll/222425/americans-no-longer-prefer-male-boss-female-boss.aspx

Brescoll, V. L., Dawson, E., \& UhImann, E. L. (2010). Hard won and easily lost: The fragile status of leaders in gender-stereotype-incongruent occupations. Psychological Science, 21(11), 16401642. https://doi.org/10.1177/0956797610384744

Brescoll, V. L., Uhlmann, E. L., \& Newman, G. E. (2013). The effects of system-justifying motives on endorsement of essentialist explanations for gender differences. Journal of Personality and Social Psychology, 105(6), 891-908. https://doi.org/10.1037/a0034701

Brinkman, R. L., \& Brinkman, J. E. (1997). Cultural lag: Conception and theory. International Journal of Social Economics, 24, 609-631.

Bussey, K., \& Bandura, A. (1999). Social cognitive theory of gender development and differentiation. Psychological Review, 106(4), 676.

Carnes, M., Devine, P. G., Isaac, C., Manwell, L. B., Ford, C. E., Byars-Winston, A., Fine, E., \& Sheridan, J. T. (2012). Promoting Institutional Change Through Bias Literacy. Journal of Diversity in Higher Education, 5(2), 63-77. https://doi.org/10.1037/a0028128

Carnes, M., Devine, P. G., Manwell, L. B., Byars-Winston, A., Fine, E., Ford, C. E., Forscher, P., Isaac, C., Kaatz, A., Magua, W., Palta, M., \& Sheridan, J. (2015). Effect of an Intervention to Break the Gender Bias Habit for Faculty at One Institution: A Cluster Randomized, Controlled Trial. Academic Medicine : Journal of the Association of American Medical Colleges, 90(2), 221-230. https://doi.org/10.1097/ACM.0000000000000552

Carothers, B. J., \& Reis, H. T. (2013). Men and women are from Earth: Examining the latent structure of gender. Journal of Personality and Social Psychology, 104(2), 385-407. https://doi.org/10.1037/a0030437

Ceci, S. J., \& Williams, W. M. (2015). Women have substantial advantage in STEM faculty hiring, except when competing against more-accomplished men. Frontiers in Psychology, 6. https://doi.org/10.3389/fpsyg.2015.01532

Chan, M., Rogers, K. H., Parisotto, K. L., \& Biesanz, J. C. (2011). Forming first impressions: The role of gender and normative accuracy in personality perception. Journal of Research in Personality, 45(1), 117-120. https://doi.org/10.1016/j.jrp.2010.11.001

Charlesworth, T. E. S., \& Banaji, M. R. (2019). Gender in Science, Technology, Engineering, and Mathematics: Issues, Causes, Solutions. Journal of Neuroscience, 39(37), 7228-7243. https://doi.org/10.1523/JNEUROSCI.0475-18.2019

Cheryan, S., \& Markus, H. R. (2020). Masculine defaults: Identifying and mitigating hidden cultural biases. Psychological Review, 127, 1022-1052. https://doi.org/10.1037/rev0000209

Cheryan, S., Plaut, V. C., Davies, P. G., \& Steele, C. M. (2009). Ambient belonging: How stereotypical cues impact gender participation in computer science. Journal of Personality and Social Psychology, 97(6), 1045. 
Cheryan, S., Siy, J. O., Vichayapai, M., Drury, B. J., \& Kim, S. (2011). Do female and male role models who embody STEM stereotypes hinder women's anticipated success in STEM? Social Psychological and Personality Science, 2(6), 656-664. https://doi.org/10.1177/1948550611405218

Cheryan, S., Ziegler, S. A., Montoya, A., \& Jiang, L. (2017). Why are some STEM fields more gender balanced than others? Psychological Bulletin, 143, 1-35.

Cho, S., Crenshaw, K. W., \& McCall, L. (2013). Toward a Field of Intersectionality Studies: Theory, Applications, and Praxis. Signs: Journal of Women in Culture and Society, 38(4), 785-810. https://doi.org/10.1086/669608

Clark, E. K., Fuesting, M. A., \& Diekman, A. B. (2016). Enhancing interest in science: Exemplars as cues to communal affordances of science. Journal of Applied Social Psychology, 46(11), 641-654. https://doi.org/10.1111/jasp.12392

Clark, J. K., Thiem, K. C., Hoover, A. E., \& Habashi, M. M. (2017). Gender stereotypes and intellectual performance: Stigma consciousness as a buffer against stereotype validation. Journal of Experimental Social Psychology, 68, 185-191. https://doi.org/10.1016/j.jesp.2016.07.002

Cole, E. R. (2009). Intersectionality and research in psychology. American Psychologist, 64, 170-180.

Crandall, C., \& Eshleman, A. (2003). A justification-suppression model of the expression and experience of prejudice. Psychological Bulletin, 129, 414-446.

Crane, M., \& Markus, H. (1982). Gender identity: The benefits of a self-schema approach. Journal of Personality and Social Psychology, 43, 1195-1197.

Crenshaw, K. (1990). Mapping the Margins: Intersectionality, Identity Politics, and Violence against Women of Color. Stanford Law Review, 43, 1241.

Croft, A., Schmader, T., \& Block, K. (2015). An underexamined inequality: Cultural and psychological barriers to men's engagement with communal roles. Personality and Social Psychology Review, 1088868314564789. https://doi.org/10.1177/1088868314564789

Cuddy, A. J. C., Fiske, S. T., \& Glick, P. (2008). Warmth and Competence as Universal Dimensions of Social Perception: The Stereotype Content Model and the BIAS Map. In Advances in Experimental Social Psychology (Vol. 40, pp. 61-149). Elsevier. https://doi.org/10.1016/S0065-2601(07)000020

Cuddy, A. J. C., Wolf, E. B., Glick, P., Crotty, S., Chong, J., \& Norton, M. I. (2015). Men as cultural ideals: Cultural values moderate gender stereotype content. Journal of Personality and Social Psychology, 109, 622-635. https://doi.org/10.1037/pspi0000027

Cvencek, D., Greenwald, A. G., \& Meltzoff, A. N. (2012). Balanced identity theory: Review of evidence for implicit consistency in social cognitoin. In B. Gawronski \& F. Strack (Eds.), Cognitive Consistency: A Fundamental Principle in Social Cognition. Guilford Press.

Cvencek, D., Meltzoff, A. N., \& Kapur, M. (2014). Cognitive consistency and math-gender stereotypes in Singaporean children. Journal of Experimental Child Psychology, 117, 73-91. https://doi.org/10.1016/j.jecp.2013.07.018

Cvencek, D., Meltzoff, A. N., Maddox, C. D., Nosek, B. A., Rudman, L. A., Devos, T., Dunham, Y., Baron, A. S., Steffens, M. C., Lane, K., Horcajo, J., Ashburn-Nardo, L., Quinby, A., Srivastava, S. B., Schmidt, K., Aidman, E., Tang, E., Farnham, S., Mellott, D. S., ... Greenwald, A. G. (2020). Meta-Analytic 
Use of Balanced Identity Theory to Validate the Implicit Association Test. Personality and Social Psychology Bulletin, 0146167220916631. https://doi.org/10.1177/0146167220916631

Darley, J. M., \& Gross, P. H. (1983). A hypothesis-confirming bias in labeling effects. Journal of Personality and Social Psychology, 44(1), 20-33. https://doi.org/10.1037/0022-3514.44.1.20

Dar-Nimrod, I., \& Heine, S. J. (2006). Exposure to scientific theories affects women's math performance. Science, 314(5798), 435-435. https://doi.org/10.1126/science.1131100

Dasgupta, N. (2011). Ingroup Experts and Peers as Social Vaccines Who Inoculate the Self-Concept: The Stereotype Inoculation Model. Psychological Inquiry, 22(4), 231-246. https://doi.org/10.1080/1047840X.2011.607313

Dasgupta, N., \& Asgari, S. (2004). Seeing is believing: Exposure to counterstereotypic women leaders and its effect on the malleability of automatic gender stereotyping. Journal of Experimental Social Psychology, 40, 642-658.

Deaux, K., \& Lewis, L. L. (1984). Structure of gender stereotypes: Interrelationships among components and gender label. Journal of Personality and Social Psychology, 46, 991-1004.

Deaux, K., \& Major, B. (1987). Putting gender into context: An interactive model of gender-related behavior. Psychological Review, 94, 369-389. https://doi.org/10.1037/0033-295X.94.3.369

DeFranza, D., Mishra, H., \& Mishra, A. (2020). How language shapes prejudice against women: An examination across 45 world languages. Journal of Personality and Social Psychology, 119(1), 722. https://doi.org/10.1037/pspa0000188

Devine, P. G. (1989). Stereotypes and prejudice: Their automatic and controlled components. Journal of Personality and Social Psychology, 56, 5-18.

Diekman, A. B., Brown, E. R., Johnston, A. M., \& Clark, E. K. (2010). Seeking congruity between goals and roles: A new look at why women opt out of science, technology, engineering, and mathematics careers. Psychological Science.

Diekman, A. B., Clark, E. K., Johnston, A. M., Brown, E. R., \& Steinberg, M. (2011). Malleability in communal goals and beliefs influences attraction to STEM careers. Journal of Personality and Social Psychology, 101, 902-918.

Diekman, A. B., \& Eagly, A. H. (2000). Stereotypes as dynamic constructs: Women and men of the past, present, and future. Personality and Social Psychology Bulletin, 26, 1171-1188. https://doi.org/10.1177/0146167200262001

Diekman, A. B., Eagly, A. H., Mladinic, A., \& Ferreira, M. C. (2005). Dynamic stereotypes about women and men in Latin America and the United States. Journal of Cross-Cultural Psychology, 36, 209226. https://doi.org/10.1177/0022022104272902

Diekman, A. B., \& Goodfriend, W. (2006). Rolling with the changes: A role congruity perspective on gender norms. Psychology of Women Quarterly, 30, 369-383. https://doi.org/10.1111/j.14716402.2006.00312.x

Diekman, A. B., Johnston, A. M., \& Loescher, A. L. (2013). Something old, something new: Evidence of self-accommodation to gendered social change. Sex Roles, 68(9-10), 550-561. https://doi.org/10.1007/s11199-013-0263-6

Diekman, A. B., Steinberg, M., Brown, E. R., Belanger, A. L., \& Clark, E. K. (2017). A goal congruity model of role entry, engagement, and exit: Understanding communal goal processes in STEM gender 
gaps. Personality and Social Psychology Review, 21(2), 142-175.

https://doi.org/10.1177/1088868316642141

Dunham, Y., Baron, A. S., \& Banaji, M. R. (2016). The development of implicit gender attitudes. Developmental Science, 19(5), 781-789. https://doi.org/10.1111/desc.12321

Eagly, A. H. (2020). Do the social roles that women and men occupy in science allow equal access to publication? Proceedings of the National Academy of Sciences, 117, 5554-5555.

Eagly, A. H., \& Karau, S. J. (2002). Role congruity theory of prejudice toward female leaders. Psychological Review, 109, 573-598.

Eagly, A. H., \& Mladinic, A. (1989). Gender stereotypes and attitudes toward women and men. Personality and Social Psychology Bulletin, 15, 543-558.

Eagly, A. H., Mladinic, A., \& Otto, S. (1991). Are women evaluated more favorably than men? An analysis of attitudes, beliefs, and emotions. Psychology of Women Quarterly, 15, 203-216.

Eagly, A. H., Nater, C., Miller, D. I., Kaufmann, M., \& Sczesny, S. (2019). Gender stereotypes have changed: A cross-temporal meta-analysis of U.S. public opinion polls from 1946 to 2018. American Psychologist. https://doi.org/10.1037/amp0000494

Eagly, A. H., \& Steffen, V. J. (1984). Gender stereotypes stem from the distribution of women and men into social roles. Journal of Personality and Social Psychology, 46, 735-754.

Eagly, A. H., \& Wood, W. (2011). Social role theory. In P. A. M. Van Lange, A. W. Kruglanski, \& E. T. Higgins (Eds.), Handbook of theories in social psychology (Vol. 2, pp. 458-476). Sage.

Eagly, A. H., \& Wood, W. (2013). The nature-nurture debates: 25 years of challenges in understanding the psychology of gender. Perspectives on Psychological Science, 8(3), 340-357. https://doi.org/10.1177/1745691613484767

Eagly, A. H., Wood, W., \& Diekman, A. B. (2000). Social role theory of sex differences and similarities: A current appraisal. In T. Eckes \& H. M. Trautner (Eds.), The developmental social psychology of gender (pp. 123-174). Erlbaum.

Eisenberg, N., \& Lennon, R. (1983). Sex differences in empathy and related capacities. Psychological Bulletin, 94(1), 100-131. https://doi.org/10.1037/0033-2909.94.1.100

Ellemers, N. (2018). Gender stereotypes. Annual Review of Psychology, 69(1), 275-298. https://doi.org/10.1146/annurev-psych-122216-011719

Else-Quest, N. M., \& Hyde, J. S. (2016). Intersectionality in quantitative psychological research: I. Theoretical and epistemological issues. Psychology of Women Quarterly, 40(2), 155-170. https://doi.org/10.1177/0361684316629797

Eyal, T., \& Epley, N. (2017). Exaggerating Accessible Differences: When Gender Stereotypes Overestimate Actual Group Differences. Personality and Social Psychology Bulletin, 43(9), 13231336. https://doi.org/10.1177/0146167217713190

Fazio, R. H., \& Towles-Schwen, T. (1999). The MODE model of attitude-behavior processes. In Dualprocess theories in social psychology (pp. 97-116). Guilford Press.

Fehr, B. (2004). Intimacy expectations in same-sex friendships: A prototype interaction-pattern model. Journal of Personality and Social Psychology, 86, 265-284.

Fiedler, K., \& Walther, E. (2004). Stereotyping as Inductive Hypothesis Testing. Psychology Press. 
Fine, C. (2010). From Scanner to Sound Bite: Issues in Interpreting and Reporting Sex Differences in the Brain. Current Directions in Psychological Science, 19(5), 280-283. https://doi.org/10.1177/0963721410383248

Fiske, S. T., Cuddy, A. J. C., Glick, P., \& Xu, J. (2002). A model of (often mixed) stereotype content: Competence and warmth respectively follow from perceived status and competition. Journal of Personality and Social Psychology, 82(6), 878-902. https://doi.org/10.1037/0022-3514.82.6.878

Fiske, S. T., Cuddy, A. J., \& Glick, P. (2007). Universal dimensions of social cognition: Warmth and competence. Trends in Cognitive Sciences, 11(2), 77-83.

Fiske, S. T., \& Stevens, L. E. (1993). What's so special about sex? Gender stereotyping and discrimination. In Oksamp, S. \& M. Costanzo (Eds.), Gender issues in contemporary society (pp. 173-196). Sage.

Forscher, P. S., Mitamura, C., Dix, E. L., Cox, W. T. L., \& Devine, P. G. (2017). Breaking the prejudice habit: Mechanisms, timecourse, and longevity. Journal of Experimental Social Psychology, 72, 133-146. https://doi.org/10.1016/j.jesp.2017.04.009

Fuesting, M. A., \& Diekman, A. B. (2017). Not by success alone: Role models provide pathways to communal opportunities in STEM. Personality and Social Psychology Bulletin, 43(2), 163-176. https://doi.org/10.1177/0146167216678857

Gawronski, B., \& Bodenhausen, G. V. (2006). Associative and propositional processes in evaluation: An integrative review of implicit and explicit attitude change. Psychological Bulletin, 132, 692-731.

Geis, F. L. (1993). Self-fulfilling prophecies: A social psychological view of gender. In A. E. Beall \& R. J. Sternberg (Eds.), The psychology of gender. (pp. 9-54). Guilford Press.

Gelman, S. A., Collman, P., \& Maccoby, E. E. (1986). Inferring Properties from Categories versus Inferring Categories from Properties: The Case of Gender. Child Development, 57(2), 396-404. JSTOR. https://doi.org/10.2307/1130595

Gelman, S. A., \& Gelman, F. G. L. H. P. of P. S. A. (2003). The Essential Child: Origins of Essentialism in Everyday Thought. Oxford University Press.

Gilbert, D. T., \& Malone, P. S. (1995). The correspondence bias. Psychological Bulletin, 117(1), 21-38. https://doi.org/10.1037/0033-2909.117.1.21

Glick, P., \& Fiske, S. T. (2001). An ambivalent alliance: Hostile and benevolent sexism as complementary justifications for gender inequality. American Psychologist, 56, 109-118. https://doi.org/10.1037/0003-066X.56.2.109

Glick, P., Gangl, C., Gibb, S., Klumpner, S., \& Weinberg, E. (2007). Defensive Reactions to Masculinity Threat: More Negative Affect Toward Effeminate (but not Masculine) Gay Men. Sex Roles, 57(1), 55-59. https://doi.org/10.1007/s11199-007-9195-3

Guarino, C. M., \& Borden, V. M. H. (2017). Faculty Service Loads and Gender: Are Women Taking Care of the Academic Family? Research in Higher Education, 58(6), 672-694. https://doi.org/10.1007/s11162-017-9454-2

Gülgöz, S., Glazier, J. J., Enright, E. A., Alonso, D. J., Durwood, L. J., Fast, A. A., Lowe, R., Ji, C., Heer, J., Martin, C. L., \& Olson, K. R. (2019). Similarity in transgender and cisgender children's gender development. Proceedings of the National Academy of Sciences, 116(49), 24480-24485. https://doi.org/10.1073/pnas.1909367116 
Haines, E. L., \& Stroessner, S. J. (2019). The role prioritization model: How communal men and agentic women can (sometimes) have it all. Social and Personality Psychology Compass, 13(12), e12504. https://doi.org/10.1111/spc3.12504

Hall, J. A., Irish, J. T., Roter, D. L., Ehrlich, C. M., \& Miller, L. H. (1994). Gender in medical encounters: An analysis of physician and patient communication in a primary care setting. Health Psychology, 13, 384-392.

Harris, J. M. (2019). Essays on the economics of gender and parenting. https://doi.org/10.7298/qtff-7095 Hehman, E., Carpinella, C. M., Johnson, K. L., Leitner, J. B., \& Freeman, J. B. (2014). Early Processing of Gendered Facial Cues Predicts the Electoral Success of Female Politicians. Social Psychological and Personality Science, 5(7), 815-824. https://doi.org/10.1177/1948550614534701

Heider, F. (1958). The Psychology of Interpersonal Relations. Erlbaum.

Heilman, M. E. (1983). Sex bias in work settings: The lack of fit model. Research in Organizational Behavior, 5, 269-298.

Heilman, M. E., \& Okimoto, T. G. (2007). Why are women penalized for success at male tasks?: The implied communality deficit. Journal of Applied Psychology, 92(1), 81-92. https://doi.org/10.1037/0021-9010.92.1.81

Henrich, J., \& Boyd, R. (2008). Division of labor, economic specialization, and the evolution of social stratification. Current Anthropology, 49(4), 715-724. https://doi.org/10.1086/587889

Herdt, G. (Ed.). (1993). Third sex, third gender: Beyond sexual dimorphism in culture and history. Zone Books.

Herek, G. M. (1986). On Heterosexual Masculinity: Some Psychical Consequences of the Social Construction of Gender and Sexuality. American Behavioral Scientist, 29(5), 563-577. https://doi.org/10.1177/000276486029005005

Hoffman, C., \& Hurst, N. (1990). Gender stereotypes: Perception or rationalization? Journal of Personality and Social Psychology, 58, 197-208.

Hollingshead, A. B., \& Fraidin, S. (2003). Gender stereotypes and assumptions about expertise in transactive memory. Journal of Experimental Social Psychology, 39, 355-363.

Hyde, J. S., Bigler, R. S., Joel, D., Tate, C. C., \& van Anders, S. M. (2019). The future of sex and gender in psychology: Five challenges to the gender binary. American Psychologist, 74(2), 171-193. https://doi.org/10.1037/amp0000307

Ickes, W., Gesn, P. R., \& Graham, T. (2000). Gender differences in empathic accuracy: Differential ability or differential motivation? Personal Relationships, 7(1), 95-109. https://doi.org/10.1111/j.14756811.2000.tb00006.x

Independent Lens. (2015). A map of gender-diverse cultures. https://www.pbs.org/independentlens/content/two-spirits_map-html/

Johnson, I. R., Pietri, E. S., Fullilove, F., \& Mowrer, S. (2019). Exploring Identity-Safety Cues and Allyship Among Black Women Students in STEM Environments. Psychology of Women Quarterly, 43(2), 131-150. https://doi.org/10.1177/0361684319830926

Johnson, K. L., \& Tassinary, L. G. (2016). Perceiving Sex Directly and Indirectly: Meaning in Motion and Morphology. Psychological Science. https://journals.sagepub.com/doi/10.1111/j.14679280.2005.01633.x 
Jost, J. T., \& Banaji, M. R. (1994). The role of stereotyping in system-justification and the production of false consciousness. British Journal of Social Psychology, 33, 1-27.

Jost, J. T., Banaji, M. R., \& Nosek, B. A. (2004). A decade of system justification theory: Accumulated evidence of conscious and unconscious bolstering of the status quo. Political Psychology, 25, 881-920.

Jost, J. T., \& Kay, A. C. (2005). Exposure to benevolent sexism and complementary gender stereotypes: Consequences for specific and diffuse forms of system justification. Journal of Personality and Social Psychology, 88, 498-509.

Judd, C. M., James-Hawkins, L., Yzerbyt, V., \& Kashima, Y. (2005). Fundamental dimensions of social judgment: Understanding the relations between judgments of competence and warmth. Journal of Personality and Social Psychology, 89, 899-913.

Jussim, L. (2012). Social perception and social reality: Why accuracy dominates bias and self-fulfilling prophecy. Oxford University Press.

Kirkland, R. A., Peterson, E., Baker, C. A., Miller, S., \& Pulos, S. (2013). Meta-analysis reveals adult female superiority in "Reading the Mind in the Eyes" Test. North American Journal of Psychology, 15(1), 121-146.

Klein, K. J. K., \& Hodges, S. D. (2001). Gender differences, motivation, and empathic accuracy: When it pays to understand. Personality \& Social Psychology Bulletin, 27, 720-730.

Klonis, S. C., Plant, E. A., \& Devine, P. G. (2005). Internal and External Motivation to Respond Without Sexism. Personality and Social Psychology Bulletin, 31(9), 1237-1249. https://doi.org/10.1177/0146167205275304

Klysing, A. (2020). Exposure to Scientific Explanations for Gender Differences Influences Individuals' Personal Theories of Gender and Their Evaluations of a Discriminatory Situation. Sex Roles, 82(5), 253-265. https://doi.org/10.1007/s11199-019-01060-w

Koenig, A. M., \& Eagly, A. H. (2005). Stereotype Threat in Men on a Test of Social Sensitivity. Sex Roles, 52(7), 489-496. https://doi.org/10.1007/s11199-005-3714-x

Koenig, A. M., \& Eagly, A. H. (2014). Evidence for the social role theory of stereotype content: Observations of groups' roles shape stereotypes. Journal of Personality and Social Psychology, 107, 371-392.

Kosakowska-Berezecka, N., Safdar, S., Jurek, P., \& Bhardwaj, G. (2018). Evaluations of Men in Domestic Roles in Canada, Norway, Poland, and India. The Journal of Men's Studies, 26(2), 143-156. https://doi.org/10.1177/1060826517734379

Kroeper, K. M., Sanchez, D. T., \& Himmelstein, M. S. (2014). Heterosexual Men's Confrontation of Sexual Prejudice: The Role of Precarious Manhood. Sex Roles, 70(1-2), 1-13. http://dx.doi.org/10.1007/s11199-013-0306-z

Kunda, Z., Davies, P. G., Adams, B. D., \& Spencer, S. J. (2002). The dynamic time course of stereotype activation: Activation, dissipation, and resurrection. Journal of Personality and Social Psychology, 82, 283-299.

Landrine, H. (1985). Race X class stereotypes of women. Sex Roles, 13, 65-. 
Levanon, A., England, P., \& Allison, P. (2009). Occupational Feminization and Pay: Assessing Causal Dynamics Using 1950-2000 U.S. Census Data. Social Forces, 88(2), 865-891. https://doi.org/10.1353/sof.0.0264

Leyens, J.-P., Désert, M., Croizet, J.-C., \& Darcis, C. (2000). Stereotype Threat: Are Lower Status and History of Stigmatization Preconditions of Stereotype Threat? Personality and Social Psychology Bulletin, 26(10), 1189-1199. https://doi.org/10.1177/0146167200262002

Lick, D. J., Johnson, K. L., \& Gill, S. V. (2013). Deliberate Changes to Gendered Body Motion Influence Basic Social Perceptions. Social Cognition, 31(6), 656-671. https://doi.org/10.1521/soco.2013.31.6.656

Lick, D. J., Johnson, K. L., \& Gill, S. V. (2014). Why Do They Have to Flaunt it? Perceptions of Communicative Intent Predict Antigay Prejudice Based Upon Brief Exposure to Nonverbal Cues. Social Psychological and Personality Science, 5(8), 927-935. https://doi.org/10.1177/1948550614537311

Logel, C., Walton, G. M., Spencer, S. J., Iserman, E. C., von Hippel, W., \& Bell, A. E. (2009). Interacting with sexist men triggers social identity threat among female engineers. Journal of Personality and Social Psychology, 96(6), 1089-1103. https://doi.org/10.1037/a0015703

Maccoby, E. E., \& Jacklin, C. N. (1974). The psychology of sex differences. Stanford University Press. Madon, S., Jussim, L., Guyll, M., Nofziger, H., Salib, E. R., Willard, J., \& Scherr, K. C. (2018). The accumulation of stereotype-based self-fulfilling prophecies. Journal of Personality and Social Psychology, 115(5), 825-844. https://doi.org/10.1037/pspi0000142

Markus, H. R., \& Kitayama, S. (2010). Cultures and selves: A cycle of mutual constitution. Perspectives on Psychological Science, 5(4), 420-430. https://doi.org/10.1177/1745691610375557

Martin, A. E., \& Slepian, M. L. (2020). The Primacy of Gender: Gendered Cognition Underlies the Big Two Dimensions of Social Cognition. Perspectives on Psychological Science. https://doi.org/10.1177/1745691620904961

Master, A., Cheryan, S., \& Meltzoff, A. N. (2016). Computing whether she belongs: Stereotypes undermine girls' interest and sense of belonging in computer science. Journal of Educational Psychology, 108(3), 424-437. https://doi.org/10.1037/edu0000061

Meerwik, E. L., \& Sevelius, J. M. (2017). Transgender Population Size in the United States: A MetaRegression of Population-Based Probability Samples. American Journal of Public Health, 107(2). https://doi.org/10.2105/AJPH.2016.303578

Meyer, M., \& Gelman, S. A. (2016). Gender Essentialism in Children and Parents: Implications for the Development of Gender Stereotyping and Gender-Typed Preferences. Sex Roles, 75(9), 409-421. https://doi.org/10.1007/s11199-016-0646-6

Miller, D. I., Eagly, A. H., \& Linn, M. C. (2015). Women's representation in science predicts national gender-science stereotypes: Evidence from 66 nations. Journal of Educational Psychology, 107(3), 631-644. https://doi.org/10.1037/edu0000005

Miller, D. I., Nolla, K. M., Eagly, A. H., \& Uttal, D. H. (2018). The development of children's genderscience stereotypes: A meta-analysis of 5 decades of U.S. draw-a-scientist studies. Child Development, 89(6), 1943-1955. https://doi.org/10.1111/cdev.13039 
Morgenroth, T., \& Ryan, M. K. (2020). The Effects of Gender Trouble: An Integrative Theoretical Framework of the Perpetuation and Disruption of the Gender/Sex Binary. Perspectives on Psychological Science, 1745691620902442. https://doi.org/10.1177/1745691620902442

Moss-Racusin, C. A., Dovidio, J. F., Brescoll, V. L., Graham, M. J., \& Handelsman, J. (2012). Science faculty's subtle gender biases favor male students. Proceedings of the National Academy of Sciences, 109. https://doi.org/10.1073/pnas.1211286109

Moss-Racusin, C. A., \& Johnson, E. R. (2016). Backlash against male elementary educators. Journal of Applied Social Psychology, 46(7), 379-393. https://doi.org/10.1111/jasp.12366

Moss-Racusin, C. A., Phelan, J. E., \& Rudman, L. A. (2010). When men break the gender rules: Status incongruity and backlash against modest men. Psychology of Men \& Masculinity, 11(2), 140151. https://doi.org/10.1037/a0018093

Moss-Racusin, C. A., \& Rudman, L. A. (2010). Disruptions in women's self-promotion: The backlash avoidance model. Psychology of Women Quarterly, 34(2), 186-202. https://doi.org/10.1111/j.1471-6402.2010.01561.x

Murphy, M. C., \& Walton, G. M. (2013). From prejudiced people to prejudiced places: A socialcontextual approach to prejudice. In C. Stangor \& C. S. Crandall (Eds.), Stereotyping and Prejudice (pp. 181-203). Psychology Press.

Neuberg, S. L., \& Fiske, S. T. (1987). Motivational influences on impression formation: Outcome dependency, accuracy-driven attention, and individuating processes. Journal of Personality and Social Psychology, 53(3), 431-444. https://doi.org/10.1037/0022-3514.53.3.431

Nosek, B. A. (2007). Implicit-Explicit Relations. Current Directions in Psychological Science, 16(2), 65-69. https://doi.org/10.1111/j.1467-8721.2007.00477.x

Nosek, B. A., Banaji, M. R., \& Greenwald, A. G. (2002). Math= male, me= female, therefore math\$ne\$ me. Journal of Personality and Social Psychology, 83(1), 44.

Nosek, B. A., Smyth, F. L., Sriram, N., Lindner, N. M., Devos, T., Ayala, A., Bar-Anan, Y., Bergh, R., Cai, H., Gonsalkorale, K., Kesebir, S., Maliszewski, N., Neto, F., Olli, E., Park, J., Schnabel, K., Shiomura, K., Tulbure, B. T., Wiers, R. W., ... Greenwald, A. G. (2009). National differences in gender-science stereotypes predict national sex differences in science and math achievement. Proceedings of the National Academy of Sciences, 106(26), 10593-10597. https://doi.org/10.1073/pnas.0809921106

O'Brien, L. T., Blodorn, A., Adams, G., Garcia, D. M., \& Hammer, E. (2015). Ethnic variation in genderSTEM stereotypes and STEM participation: An intersectional approach. Cultural Diversity and Ethnic Minority Psychology, 21(2), 169.

Oh, D., Buck, E. A., \& Todorov, A. (2019). Revealing Hidden Gender Biases in Competence Impressions of Faces. Psychological Science, 30(1), 65-79. https://doi.org/10.1177/0956797618813092

Okimoto, T. G., \& Brescoll, V. L. (2010). The price of power: Power seeking and backlash against female politicians. Personality and Social Psychology Bulletin, 36(7), 923-936. https://doi.org/10.1177/0146167210371949

Olson, K. R., Key, A. C., \& Eaton, N. R. (2015). Gender Cognition in Transgender Children. Psychological Science, 26(4), 467-474. https://doi.org/10.1177/0956797614568156 
Park, B., \& Banchefsky, S. (2019). Women and men, moms and dads: Leveraging social role change to promote gender equality. In J. M. Olson (Ed.), Advances in Experimental Social Psychology (Vol. 59, pp. 1-52). https://doi.org/10.1016/bs.aesp.2018.10.001

Payne, B. K., Vuletich, H. A., \& Lundberg, K. B. (2017). The Bias of Crowds: How Implicit Bias Bridges Personal and Systemic Prejudice. Psychological Inquiry, 28(4), 233-248. https://doi.org/10.1080/1047840X.2017.1335568

Pietri, E. S., Drawbaugh, M. L., Lewis, A. N., \& Johnson, I. R. (2019). Who encourages Latina women to feel a sense of identity-safety in STEM environments? Journal of Experimental Social Psychology, 84, 103827. https://doi.org/10.1016/j.jesp.2019.103827

Pinel, E. C. (2002). Stigma consciousness in intergroup contexts: The power of conviction. Journal of Experimental Social Psychology, 38, 178-185.

Prentice, D. A., \& Carranza, E. (2002). What women should be, shouldn't be, are allowed to be, and don't have to be: The contents of prescriptive gender stereotypes. Psychology of Women Quarterly, 26, 269-281.

Pronin, E., Steele, C. M., \& Ross, L. (2004). Identity bifurcation in response to stereotype threat: Women and mathematics. Journal of Experimental Social Psychology, 40(2), 152-168.

Régner, I., Thinus-Blanc, C., Netter, A., Schmader, T., \& Huguet, P. (2019). Committees with implicit biases promote fewer women when they do not believe gender bias exists. Nature Human Behaviour, 1-9. https://doi.org/10.1038/s41562-019-0686-3

Ridgeway, C. L. (1992). Gender, interaction, and inequality. Springer. http://books.google.com/books?hl=en\&lr=\&id=t5Tq93uVaKwC\&oi=fnd\&pg=PR9\&dq=ridgeway+ diekema\&ots=NvfOdTUlv1\&sig=Cpv_0g8RyXcPLUF1QeRiUEiyCQI

Ridinger, G., \& McBride, M. (2015). Money Affects Theory of Mind Differently by Gender. PLoS ONE, 10(12). https://doi.org/10.1371/journal.pone.0143973

Roberts, S. O., Ho, A. K., Rhodes, M., \& Gelman, S. A. (2017). Making Boundaries Great Again: Essentialism and Support for Boundary-Enhancing Initiatives. Personality and Social Psychology Bulletin, 43(12), 1643-1658. https://doi.org/10.1177/0146167217724801

Rosette, A. S., Koval, C. Z., Ma, A., \& Livingston, R. (2016). Race matters for women leaders: Intersectional effects on agentic deficiencies and penalties. The Leadership Quarterly, 27(3), 429-445. https://doi.org/10.1016/j.leaqua.2016.01.008

Rudman, L. A., \& Fairchild, K. (2004). Reactions to counterstereotypic behavior: The role of backlash in cultural stereotype maintenance. Journal of Personality and Social Psychology, 87, 157-176.

Rudman, L. A., \& Glick, P. (2001). Prescriptive gender stereotypes and backlash toward agentic women. Journal of Social Issues, 57, 743-762.

Rudman, L. A., \& Glick, P. S. (2008). The Social Psychology of Gender: How Power and Intimacy Shape Gender Relations. Guilford Press.

Rudman, L. A., \& Goodwin, S. A. (2004). Gender differences in automatic in-group bias: Why do women like women more than men like men? Journal of Personality and Social Psychology, 87, 494-509.

Rudman, L. A., Greenwald, A. G., \& McGhee, D. E. (2001). Implicit self-concept and evaluative implicit gender stereotypes: Self and ingroup share desirable traits. Personality and Social Psychology Bulletin, 27, 1164-1178. 
Rudman, L. A., Moss-Racusin, C. A., Glick, P., \& Phelan, J. E. (2012). Reactions to Vanguards: Advances in Backlash Theory. In P. G. Devine \& A. Plant (Eds.), Advances in Experimental Social Psychology (Vol. 45, pp. 167-227). Academic Press. https://doi.org/10.1016/B978-0-12-394286-9.00004-4

Schmader, T., \& Block, K. (2015). Engendering Identity: Toward a Clearer Conceptualization of Gender as a Social Identity. Sex Roles, 73(11), 474-480. https://doi.org/10.1007/s11199-015-0536-3

Schmader, T., Major, B., Eccleston, C. P., \& McCoy, S. K. (2001). Devaluing domains in response to threatening intergroup comparisons: Perceived legitimacy and the status value asymmetry. Journal of Personality and Social Psychology, 80(5), 782-796. https://doi.org/10.1037/00223514.80.5.782

Schmader, T., \& Sedikides, C. (2018). State authenticity as fit to environment: The implications of social identity for fit, authenticity, and self-segregation. Personality and Social Psychology Review, 22, 228-259. https://doi.org/10.1177/1088868317734080

Schmukle, S. C., Liesenfeld, S., Back, M. D., \& Egloff, B. (2007). Second to fourth digit ratios and the implicit gender self-concept. Personality and Individual Differences, 43(5), 1267-1277. https://doi.org/10.1016/j.paid.2007.03.018

Sczesny, S., Nater, C., \& Eagly, A. H. (2019). Agency and communion: Their implications for gender stereotypes and gender identities. In A. E. Abele \& B. Wojciszke (Eds.), Agency and Communion in Social Psychology (pp. 103-116). Routledge. https://boris.unibe.ch/119396/

Sidanius, J., \& Pratto, F. (1999). Social dominance: An intergroup theory of social hierarchy and oppression. Cambridge University Press.

Sinclair, L., \& Kunda, Z. (2000). Motivated stereotyping of women: She's fine if she praised me but incompetent if she criticized me. Personality and Social Psychology Bulletin, 26, 1329-1342.

Six, B., \& Eckes, T. (1991). A closer look at the complex structure of gender stereotypes. Sex Roles, 24(12), 57-71.

Skrypnek, B. J., \& Snyder, M. (1982). On the self-perpetuating nature of stereotypes about women and men. Journal of Experimental Social Psychology, 18, 277-291.

Snyder, M. (1992). Motivational foundations of behavioral confirmation. Advances in Experimental Social Psychology, 25, 67-114.

Sparkman, G., \& Walton, G. M. (2017). Dynamic norms promote sustainable behavior, even if it is counternormative. Psychological Science, 0956797617719950. https://doi.org/10.1177/0956797617719950

Spence, J. T., \& Helmreich, R. (1978). Masculinity and femininity: Their psychological dimensions, correlates, and antecedents. University of Texas Press.

Stangor, C., Lynch, L., Duan, C., \& Glas, B. (1992). Categorization of individuals on the basis of multiple social features. Journal of Personality and Social Psychology, 62(2), 207-218. https://doi.org/10.1037//0022-3514.62.2.207

Steinberg, M., \& Diekman, A. B. (2018). Considering "why" to engage in STEM activities elevates communal content of STEM affordances. Journal of Experimental Social Psychology, 75, 107114. https://doi.org/10.1016/j.jesp.2017.10.010

Stout, J. G., Dasgupta, N., Hunsinger, M., \& McManus, M. A. (2011). STEMing the tide: Using ingroup experts to inoculate women's self-concept in science, technology, engineering, and mathematics 
(STEM). Journal of Personality and Social Psychology, 100(2), 255-270.

https://doi.org/10.1037/a0021385

Stroessner, S. J., Benitez, J., Perez, M. A., Wyman, A. B., Carpinella, C. M., \& Johnson, K. L. (2020). What's in a shape? Evidence of gender category associations with basic forms. Journal of Experimental Social Psychology, 87, 103915. https://doi.org/10.1016/j.jesp.2019.103915

Sutherland, C. A. M., Young, A. W., Mootz, C. A., \& Oldmeadow, J. A. (2015). Face gender and stereotypicality influence facial trait evaluation: Counter-stereotypical female faces are negatively evaluated. British Journal of Psychology (London, England: 1953), 106(2), 186-208. https://doi.org/10.1111/bjop.12085

Taylor, S. E., Fiske, S. T., Etcoff, N. L., \& Ruderman, A. J. (1978). Categorical and contextual bases of person memory and stereotyping. Journal of Personality and Social Psychology, 36(7), 778-793. https://doi.org/10.1037/0022-3514.36.7.778

van Anders, S. M. (2015). Beyond Sexual Orientation: Integrating Gender/Sex and Diverse Sexualities via Sexual Configurations Theory. Archives of Sexual Behavior, 44(5), 1177-1213. https://doi.org/10.1007/s10508-015-0490-8

Van Grootel, S., Van Laar, C., Meeussen, L., Schmader, T., \& Sczesny, S. (2018). Uncovering Pluralistic Ignorance to Change Men's Communal Self-descriptions, Attitudes, and Behavioral Intentions. Frontiers in Psychology, 9. https://doi.org/10.3389/fpsyg.2018.01344

Vandello, J. A., Bosson, J. K., Cohen, D., Burnaford, R. M., \& Weaver, J. R. (2008). Precarious manhood. Journal of Personality and Social Psychology, 95(6), 1325-1339. https://doi.org/10.1037/a0012453

Vial, A. C., Brescoll, V. L., \& Dovidio, J. F. (2019). Third-party prejudice accommodation increases gender discrimination. Journal of Personality and Social Psychology, 117(1), 73-98. https://doi.org/10.1037/pspi0000164

Wilkie, J. E. B., \& Bodenhausen, G. V. (2012). Are numbers gendered? Journal of Experimental Psychology: General, 141(2), 206-210. https://doi.org/10.1037/a0024875

Williams, M. J., \& Tiedens, L. Z. (2016). The subtle suspension of backlash: A meta-analysis of penalties for women's implicit and explicit dominance behavior. Psychological Bulletin, 142(2), 165-197. https://doi.org/10.1037/bul0000039

Williams, W. M., \& Ceci, S. J. (2015). National hiring experiments reveal 2:1 faculty preference for women on STEM tenure track. Proceedings of the National Academy of Sciences, 201418878. https://doi.org/10.1073/pnas.1418878112

Wood, W., \& Eagly, A. H. (2002). A cross-cultural analysis of the behavior of women and men: Implications for the origins of sex differences. Psychological Bulletin, 128, 699-727. https://doi.org/10.1037/0033-2909.128.5.699

Wood, W., \& Eagly, A. H. (2015). Two Traditions of Research on Gender Identity. Sex Roles, 73(11), 461473. https://doi.org/10.1007/s11199-015-0480-2 